AFFECTIVE POLARIZATION ON SOCIAL MEDIA

Affective polarization on social media: In-party love among American politicians, greater engagement with out-party hate among ordinary users

\author{
Xudong Yu \\ Magdalena Wojcieszak \\ Andreu Casas
}

Xudong $\mathrm{Yu}$ is a $\mathrm{PhD}$ candidate at Department of Communication, University of California, Davis, Davis, CA, USA. Magdalena Wojcieszak is a Professor at Department of Communication, University of California, Davis, Davis, CA, USA and an Associate Researcher (Principal Investigator, ERC SG) at the University of Amsterdam, Amsterdam, the Netherlands. Andreu Casas is an Assistant Professor at Department of Communication Science, Free

University of Amsterdam, Amsterdam, the Netherlands. Address correspondence to One Shields Avenue, Kerr Hall 154, Davis, CA 95616, email xdyu@ucdavis.edu.

Acknowledgements: The authors would like to thank Yphtach Lelkes and Amber Boydstun for their insightful comments and suggestions. 
AFFECTIVE POLARIZATION ON SOCIAL MEDIA

\title{
Affective polarization on social media: In-party love among American politicians, greater engagement with out-party hate among ordinary users
}

\begin{abstract}
Americans view their in-party members positively and out-party members negatively. It remains unclear, however, whether in-party love (i.e., positive partisanship) or out-party hate (i.e., negative partisanship) more strongly influences political attitudes and behaviors. Unlike past work, which relies on survey self-reports or experimental designs among ordinary citizens, this pre-registered project examines actual social media expressions of an exhaustive list of American politicians as well as citizens' engagement with these posts. Relying on 1,195,844 tweets sent by 564 political elites (i.e., members of US House and Senate, Presidential and VicePresidential nominees from 2000 to 2020, and members of the Trump Cabinet) and machine learning to reliably classify the tone of the tweets, we show that elite expressions online are driven by positive partisanship: politicians are more likely to post tweets positive toward their inparty than tweets negative toward the out-party. However, more ideologically extreme politicians and those in the opposition (i.e., the Democrats) are more negative toward the out-party than those ideologically moderate and whose party is in power. Furthermore, examining how Twitter users react to these messages, we find that negative partisanship plays a greater role in online engagement among ordinary citizens (i.e., users are more likely to like and share politicians' tweets negative toward the out-party than tweets positive toward the in-party). This project has important theoretical and democratic implications, and extends the use of trace data and computational methods in political communication.

Keywords: Affective Polarization, Political Expression, Citizen Engagement, Social Media, Partisanship
\end{abstract}


AFFECTIVE POLARIZATION ON SOCIAL MEDIA

\section{Affective polarization on social media: In-party love among American politicians, greater engagement with out-party hate among ordinary users}

According to some observers, America has not been as divided since the Civil War (Brownstein, 2021; Manchester, 2018). Democrats and Republicans like their fellow co-partisans and hate the opposition (see Iyengar et al., 2019). This favoritism toward one's own party is also known as in-party love or positive partisanship, and the hostility against the opposing party is dubbed out-party hate or negative partisanship. The growing gap between how ordinary voters feel toward their own versus the opposing party has important consequences: it reduces trust in the government run by the opposition (Hetherington \& Rudolph, 2015), shapes individual beliefs about political issues (Druckman et al., 2020), and can influence attitudes and behaviors in nonpolitical contexts, such as evaluations of college applicants (Iyengar \& Westwood, 2015) or another person's physical attractiveness (Nicholson et al., 2016; see also Broockman et al., 2020).

Despite the burgeoning research, it is unclear whether biased attitudes and behaviors mentioned above are caused by positive or negative partisanship. If the admission committee awards scholarship to the candidate who shares their partisanship, is that primarily because they prefer and want to help the in-party member or dislike and want to disadvantage an out-party candidate? Some scholars argue that positive partisanship is a stronger driver of individual attitudes and behaviors (Amira et al., 2019; Lelkes \& Westwood, 2017), others find that negative partisanships matters more (Abramowitz \& Webster, 2016; Iyengar \& Krupenkin, 2018), and yet other work suggests that whether positive or negative partisanship exerts stronger effects on political behavior depends on the behavior itself, such as volunteering for a party versus 
AFFECTIVE POLARIZATION ON SOCIAL MEDIA

participating in a protest (Bankert, 2020; Caruana et al., 2015; Iyengar et al., 2019), as we detail below.

This previous work offers important evidence on the intricacies of interparty attitudes and affective polarization more specifically. The key gaps of this work, however, are its exclusive focus on "ordinary" citizens and - most typically - their attitudes as reported on survey questionnaires or gauged by observing various behaviors in experimental settings. This preregistered project uses online behavioral data from Twitter to advance past work by investigating whether elite expressions on social media are mainly motivated by positive or negative partisanship (i.e., are American politicians more likely to praise their in-group or criticize the out-group?). To our knowledge, our research is the first to systematically investigate how politicians, ranging from representatives, senators to presidential Democratic and Republican candidates and Presidents, including Donald Trump and Joe Biden, talk about their own and opposing party as well as other politicians in their social media posts. We also examine whether these online expressions vary by ideological extremity of the political actor and also by whether their party is in power or in opposition. ${ }^{1}$

Furthermore, in addition to examining the prevalence of and the factors influencing positive and negative partisanship in online expressions of political elites, we investigate what role that positive and negative partisanship play in citizen engagement with elite messages (i.e., are ordinary Twitter users liking and sharing elite posts that praise the in-group more or less than posts that criticize the out-group?).

\footnotetext{
${ }^{1}$ We acknowledge that because the Democratic Party was always the opposition party during the timeframe of our data (2016-2020), we cannot differentiate the effects of the status of the party and partisanship. We address this issue in the discussion.
} 
AFFECTIVE POLARIZATION ON SOCIAL MEDIA

In short, we study elite expressions and people's reactions together in one study. We utilize behavioral trace data from Twitter, as this is the key platform for elite expressions politicians are more active on Twitter than on other social media platforms (Pew, 2021b). Besides, Twitter users get news on the site regularly (Pew, 2021a), are frequently used as exemplars of public opinion in "traditional" media (McGregor, 2020), and anecdotal evidence also suggests that journalists often rely on politicians' tweets in their reporting, leading these messages to exert great influence on US politics especially after Trump took office.

Relying on tweets sent by an extensive list of American politicians (i.e., 564 politicians including members of the 116th Congress, Presidential and Vice-Presidential nominees from 2000 to 2020, and members of the Trump Cabinet), our pre-registered analyses find that elite expressions on social media are primarily motivated by positive partisanship - politicians prefer to praise their own party than criticize the other party. We find two exceptions to this aggregate pattern: as predicted, politicians who are more ideologically extreme (as determined by two validated approaches, namely DW-NOMINATE (Poole \& Rosenthal, 1997) scores and also Barberá's (2015) Bayesian spatial following model) as well as those whose political party is in the opposition (i.e., Democrats in our study) are more negative toward the out-party than their more ideologically moderate counterparts and those whose party is in power. In short, contrary to popular concerns with elite hostility toward the opposing party, most American politicians focus on promoting their own party on social media, not on bashing the opposition.

Shedding important light on how citizens react to these elite expressions, we show that people engage more with elite tweets negative toward the opposition, both when it comes to liking and sharing these tweets. These robust patterns emerge regardless of how many followers and friends a politician had, across numerous issues, ranging from economy to civil rights, and 
AFFECTIVE POLARIZATION ON SOCIAL MEDIA

across different times of the day a tweet was posted. That is, ordinary users engage with negative partisanship in elite messages, falling into the well documented negativity bias. It appears, therefore, that it is not (only) elite affective polarization (as determined by actual online expressions) that is to blame for the ills of contemporary America; it is the biases in social media users themselves (namely disproportionate attention to hostility toward the opposing party).

\section{Affective Polarization and Elite Expression}

Affective polarization, or "the tendency of people identifying as Republicans or Democrats to view opposing partisans negatively and copartisans positively" (Iyengar \& Westwood, 2015, p. 691), is a hot topic in political science and communication. Whereas many studies document the causes and effects of this phenomenon, fewer systematically consider its two essential and distinct components: love for the in-party, i.e., positive partisanship, and hatred for the out-party, i.e., negative partisanship. Positive partisanship, or the psychological attachment to one's political party (Campbell et al., 1980), is an affirmational identity, which is defined by what we represent (e.g., Democrats) and leads to greater assimilation to the in-group (e.g., the in-party in our case) than differentiating from the out-group (e.g., the out-party; Zhong, Galinsky, et al., 2008; Zhong, Phillips, et al., 2008). Thus, the in-group is psychologically primary, leading to ingroup favoritism, which does not necessarily imply prejudice against the outgroup (Allport, 1954; Brewer, 1999). Consequently, individuals with positive group identity are motivated to help the in-group rather than to attack the out-group when having the chance (Brewer, 1999).

In turn, negative partisanship, or "an affective repulsion from that party" (Caruana et al., 2015, p. 772), is a negational identity, which is defined by who we are not (e.g., not Democrats; Zhong, Galinsky, et al., 2008; Zhong, Phillips, et al., 2008). With negational identities, the out- 
AFFECTIVE POLARIZATION ON SOCIAL MEDIA

groups become the core reference point, encouraging individuals to differentiate themselves from the out-group to a greater extent than to assimilate to the in-group (Zhong, Phillips, et al., 2008). Therefore, when individuals with negative group identity have the opportunity, they tend to harm out-group members rather than benefit their in-group (Zhong, Phillips, et al., 2008).

Some scholars claim that contemporary American politics is characterized by positive partisanship, which is the culprit of partisan bias. The vast majority of partisans identify more with their own party rather than against the opposite side (Theodoridis, 2019), and this in-party love has greater effects on vote choice (Bankert, 2020; Caruana et al., 2015; Medeiros \& Noël, 2014) and what news partisans want to disseminate (i.e., recommending to publish an article favoring the in-party versus an article criticizing the out-party; Amira et al., 2019; suppressing an article hostile toward the in-party versus promoting an article attacks the out-party, Lelkes \& Westwood, 2017). Other work, however, suggests negative partisanship exceeds positive partisanship (Finkel et al., 2020) and drives political cognitions and behaviors. Out-party hate is a stronger predictor of voting and other forms of political participation (Abramowitz \& Webster, 2016; Iyengar \& Krupenkin, 2018) and also of one's satisfaction with the functioning of democracy (Ridge, 2020).

Yet other studies suggest that both positive and negative partisanship are strong among American citizens and which one primarily drives political activities varies by behavior. Surveys show that most partisans affiliate with their party because they love their own party's policies and hate the other party's policies (Pew, 2018b) and that 64\% of US partisans display high levels of both positive and negative partisanship (Bankert, 2020). Positive partisanship encourages political engagement advancing one's party (e.g., volunteering for one's own party); negative 
AFFECTIVE POLARIZATION ON SOCIAL MEDIA

partisanship, on the other hand, exerts greater influence on opposition-oriented attitudes and activities such as anti-bipartisanship and protesting (Bankert, 2020; Caruana et al., 2015).

This literature sheds important light on the complexities and the effects of affective polarization. Nevertheless, this work has two major limitations. For one, it focuses on rank-andfile partisans and overlooks political elites. ${ }^{2}$ Are the political expressions of politicians primarily driven by positive or negative partisanship? Needless to say, members of Congress, Presidential and Vice-Presidential nominees, and members of the Cabinet have a much greater influence over the political process than the majority of citizens. Elite communication shapes citizens' opinions (Druckman et al., 2013; Levendusky, 2010) and behaviors (e.g., enhancing partisan identities and stereotypes, intensifying affective polarization, Iyengar et al., 2012; promoting participation, Jackson \& Carsey, 2007). More specifically, studying elite communication on social media is crucial because politicians produce an overwhelming majority of political content and dominate political discussions on social media (Barberá et al., 2019). Also, social media platforms afford politicians the most direct and unfiltered channel of communication with the voters, which can have large scale democratic consequences, as evidenced by tweets by former President Trump said to have instigated the 2021 storming of the United States Capitol.

Second, existing research relies heavily on traditional survey self-reports to measure positive and negative partisanship. Self-reports have well-known limitations, such as response biases, which may overestimate or - conversely - underestimate positive and negative partisanship due to normative pressures (Iyengar et al., 2019) and question wording (Druckman \& Levendusky, 2019; Kingzette, 2021). Although experimental designs address this problem,

\footnotetext{
${ }^{2}$ Webster (2020) examines politicians' expressions on social media, but he only looks at how 15 presidential candidates in the 2016 election expressed anger toward their in-party and out-party competitors.
} 
AFFECTIVE POLARIZATION ON SOCIAL MEDIA

their findings often lack external validity. Experimental settings are quite different from the real world, particularly when participants are forced to make decisions.

We address both gaps, studying elite messages online as well as individual reactions to these messages side by side in one project. The unprecedented ability to collect online trace data allows researchers to study actual expressions and engagement in a naturalistic environment, and - when combined with machine learning approaches to automatically and at-scale classify content - can shed light on the role of positive and negative partisanship in motivating elite expressions and citizen engagement. These expressions and engagement, as tracked behaviorally, are straightforward proxies for positive and negative partisanship. If these behaviors are primarily driven by positive partisanship, politicians will be more likely to praise their own party than bash the opposition and messages praising the in-party will get more likes and shares, and vice versa for negative partisanship. Thus, expressions and engagement are advantageous over other frequently studied behaviors, for which the effects of positive partisanship are often entangled with those of negative partisanship. For instance, it is difficult to know whether someone voted for Joe Biden in 2020 mainly because s/he loved the Democratic Party or hated the Republican Party.

We expect that elite expressions are more strongly driven by negative partisanship because political identities of politicians are constantly threatened. Politicians (and their party) are frequently challenged and attacked by pundits and journalists and by other politicians and citizens on traditional and social media (e.g., Berry \& Sobieraj, 2013; Geer, 2008, 2012; Le et al., 2017; Puglisi \& Snyder Jr, 2011). Under such circumstances, promoting their own party may not be enough, and politicians need to strike back to win the game (Amira et al., 2019). Indeed, politicians who are attacked employ more negative campaigning, responding to each attack with 
AFFECTIVE POLARIZATION ON SOCIAL MEDIA

an attack (Iyengar, 2018; Lau \& Pomper, 2001), although there is little evidence that negative campaigns are effective in getting votes (see Lau \& Rovner, 2009; Lau et al., 2007 for metaanalyses). In a study directly relevant to ours, Pew (2018a) examined lawmakers' Facebook posts mentioning Obama, Clinton, Trump, and the Democratic and the Republican parties, finding that they are more likely to express opposition toward the out-party than support for their in-party. Based on the foregoing discussion, we propose:

H1: Political actors are more likely to publish posts negative toward the opposite party than posts positive toward their own party on social media.

In addition to this aggregate effect, we expect heterogeneous effects dependent on two factors. First, ideologically extreme political elites should exhibit stronger negative partisanship, in that they reject the characteristics of the out-party most strongly (Ridge, 2020). In the tested contexts, politicians who are more extreme should be more likely to attack the out-party than moderate politicians. Offering some suggestive support for our expectation, Pew found that the $10 \%$ most liberal and $10 \%$ most conservative legislators are more likely to attack the opposition than moderates (i.e., the $20 \%$ in the middle) on Facebook (2018a). We test ideological extremity in two validated ways, as noted below.

Second, negative partisanship should be more pronounced among members of the oppositional party, or Democrats in this case. Partisan identity of oppositional politicians is threatened to a greater extent compared to that of the ruling party members, resulting in a heightened negative partisanship and a stronger desire to lash out at the out-party. For instance, challengers are more likely to engage in negative campaigning and sponsor attack ads than incumbents (Gelman et al., 2020; Lau \& Pomper, 2001). Because the Democratic Party was the minority party in the Senate and was not in the White House from 2016 to 2020 (the timeframe 
AFFECTIVE POLARIZATION ON SOCIAL MEDIA

from which we collected the data), Democrats' partisan identity was endangered. Indeed, research has shown that negative partisanship was a stronger motivator for Democratic voters in the 2018 House election (Bankert, 2020). Therefore, our next pre-registered hypotheses predict:

H2: Negative partisanship is stronger among politicians who are ideologically extreme such that they are more likely to publish posts negative toward the opposite party than those who are ideologically moderate.

H3: Negative partisanship is stronger among Democratic politicians such that they are more likely to publish posts negative toward the opposite party than Republican politicians.

\section{Affective polarization and citizens' reactions}

In addition to looking at the prevalence of positive and negative partisanship in elite communications, the second objective of this project is to examine how the general public reacts to politician's messages on social media. If users engage more when politicians express out-party hate than in-party love, politicians would be encouraged to continue to attack the opposition, resulting in yet more toxic political climate and greater out-party hostilities. Further, the visibility of elite posts is increased when people engage with them. If elite posts attacking the opposition receive more likes and shares, more users would encounter these posts, perceive the political climate as polarized, and develop a more negative attitude toward the opposition as a result (Levendusky \& Malhotra, 2016).

Which messages by politicians should be most liked and shared? On one hand, according to the negativity bias theory, humans are evolutionarily more likely to respond to negative than positive environmental stimuli (Rozin \& Royzman, 2001; Soroka \& McAdams, 2015). This pattern, demonstrated across a variety of contexts and situations, also applies to individuals' media consumption: negative content generates stronger and more sustained reactions than 
AFFECTIVE POLARIZATION ON SOCIAL MEDIA

positive content (Soroka et al., 2019; Soroka \& McAdams, 2015). It follows that ordinary users will be more attentive and attracted to expressions of negative partisanship (i.e., posts attacking the out-party) than to expressions of positive partisanship (i.e., posts praising the in-party), which would result in greater engagement (i.e., likes and shares).

On the other hand, it is possible that tweets praising the in-party generate greater engagement. Ordinary citizens may mostly follow congenial accounts on social media and discuss politics with their partisan in-group (e.g., Bakshy et al., 2015; Cinelli et al., 2021; Himelboim et al., 2013), thus avoiding threats to their partisan identity. Therefore, their negative feelings toward the out-party may not be salient, which could lead to the preference to benefit the in-party (e.g., liking and sharing posts praising the in-party) rather than to hurt the out-party (e.g., liking and sharing posts attacking the out-party, Amira et al., 2019; Lee et al., 2021). Indeed, ordinary Democrats and Republicans prefer to publish an article (make it seen by others, akin to sharing and liking) praising their own side rather than that attacking the out-party when their partisan identities are not threatened (Amira et al., 2019). Thus, given these distinct possibilities, we advance the following question:

$R Q 1:$ Will posts positive toward one's own party or posts negative toward the opposite party get more likes and shares? ${ }^{3}$

\section{Method}

\section{Data}

To test our hypotheses, a pre-registered study (https://osf.io/hn2f5) ${ }^{4}$ was carried out in October, 2020. We used the Twitter API to collect the timelines of then members of the House

\footnotetext{
${ }^{3}$ We are unable to test the heterogeneous effects in this context because we cannot get the list of users who like and share politicians' posts.

${ }^{4}$ We report and explain deviations from the pre-registration in Appendix C.
} 
and Senate (i.e., the 116th Congress) as well as other influential politicians (i.e., Presidential and Vice-Presidential nominees of the two major parties from 2000 - 2020 and then members of the Trump Cabinet). We started with an existing dataset of official social media accounts for members of the 116th Congress, maintained by the @unitedstates project (https://github.com/unitedstates/congress-legislators). A research assistant manually added official Twitter accounts of the remaining politicians and personal/campaign accounts of all national political actors (e.g., for Rep. Alexandria Ocasio-Cortez, both her official account @ RepAOC and personal account @AOC were included). ${ }^{5}$ The most recent 3,200 tweets sent by each of those accounts were collected, excluding retweets and quote tweets ${ }^{6}$ as well as those posted before the 2016 presidential election to avoid the history effect. The final sample has $1,195,844$ tweets sent by 1018 accounts owned by 564 elites with the first tweet sent on November 9, 2016 and the last tweet on October 29, 2020.

\section{Measures}

To examine whether political elites prefer to attack their opponents or praise their own party on Twitter, we first need to determine whether a tweet discussed the two major parties or party elites. A dictionary approach was adopted, such that for each of the two major parties, we created a list of keywords consisting of full names, nicknames, and Twitter handles of political elites of that party and the party itself and searched tweets mentioning these keywords within our

\footnotetext{
${ }^{5}$ Some politicians did not have verified Twitter accounts (e.g., William Barr, the Attorney General). Rep. Justin Amash was excluded because he switched to the Libertarian Party, making it difficult to determine who his in-party and out-party members were. Sen. Bernard Sanders and Sen. Angus King Jr., although identified as independents, were imputed as Democrats because they caucused with the Democrats. It should also be noted that some had never tweeted using the official/personal account (e.g., Rep. Roger Marshall had never posted on his official account (a) RepMarshall when the data were collected).

${ }^{6}$ Retweets and quote tweets were excluded for two reasons. First, retweeting is not a direct form of opinion expression. Second, the frequency of retweeting and quoting in-party positively and out-party negatively is not only influenced by positive and negative partisanship, but also by the number of in-party and out-party accounts politicians follow. For example, if one only follows in-party members, then despite his strong dislike for the opponents, he is likely to quote the in-party positively and never quote the out-party negatively.
} 
dataset. ${ }^{7}$ That is, if a tweet included any of the Republican keywords such as "Donald Trump", “drumpf", "GOP”, or "Republican," we assumed that it was directed at the Republican Party ( $n$ tweets discussed the Democratic Party $=109,840 ; n$ tweets discussed the Republican Party $=$ 151,429). ${ }^{8}$ Given the focus of this project, tweets that did not mention either party or key politicians from the party were excluded from analysis. We then converted the target of the tweets from the Democratic and/or Republican Party to in-party and/or out-party, determined by the consistency of politicians' party affiliation with the party they tweeted about (e.g., in-party if a Republican senator's tweet discussed the Republican Party).

The next step is to establish the sentiment of the tweets to determine whether they were positive toward the in-party (i.e., positive partisanship) or out-party, neutral toward the in-party or out-party, or negative toward the in-party or out-party (i.e., negative partisanship). To do so, two trained coders manually annotated a random sample of tweets $(n=10,000$, with $50 \%$ tweets targeting each party) for whether they were negative, neutral, or positive toward the targeted party. ${ }^{9}$ We used these labeled data to train five machine learning models separately for posts targeting the Democratic and the Republican Party, predicting the tone of the remaining tweets: (a) a K-Nearest-Neighbor model, (b) a Decision Tree, (c) a Gradient Boosting Machine, (d) a Support Vector Machine, and (e) a Random Forest model. We transformed the text to lowercase,

\footnotetext{
${ }^{7}$ We used full names rather than first names and last names separately because some politicians from the opposite parties have the same first or last names, making it impossible to determine which politician/party a tweet was referring to. Nicknames were collected by searching "Twitter handle + nickname." These nicknames were then searched individually on Twitter and those that were popular and exclusive were included in the final list. It should also be noted that some politicians do not have well-known, exclusive nicknames while others have several.

${ }^{8} 24,673$ tweets discussed both parties. We duplicated these tweets and used one to predict the attitude toward the Democratic Party and another to predict the attitude toward the Republican Party (see details below).

${ }^{9}$ Krippendorff's alpha $=.839$ and .795 for attitudes toward the Democratic Party and the Republican Party respectively.
} 
removed URLs, numbers, punctuations, stopwords, and non-ASCII characters, and lemmatized the remaining tokens to create an IF-TDF matrix with a sparsity of $.998 .{ }^{10}$

The accuracy of the algorithms was tested using 5-fold cross-validation and an 80/20 train-test split. Appendix A shows the overall accuracy of each of the five classifiers and the ability of each classifier to predict each target category in particular. For classifiers predicting attitudes toward the Democratic Party, the GBM achieved a high overall accuracy and a better balance between precision and recall - meaning the probabilities of false positive and false negative are roughly equal - for all three categories. Thus, we used the GBM classifier to predict the tone of tweets discussing the Democratic Party. For the same reasons, we selected the Random Forest classifier to predict the attitude of tweets targeting the Republican Party. ${ }^{11}$

We then used two different approaches to measure ideological extremity to test its effects on the expressions of positive and negative partisanship in the tweets. First, we used the dataset maintained by Voteview (Lewis et al., 2020) to get the DW-NOMINATE scores for members of the House and Senate (other political elites do not have a DW-NOMINATE score). DWNOMINATE is an estimate of ideology that places lawmakers on a liberal (-1) vs. conservative $(+1)$ scale based on their voting decisions. We created a continuous ideological extremity variable by (1) calculating the average DW-NOMINATE score for all actors, (2) calculating the difference for each actor between the average score and the score of the actor, (3) extracting the absolute value for this difference, and (4) rescaling it between 0 to 1 as the ideological extremity score $(M=0.46, S D=0.17)$. Second, we also used Barberá's (2015) validated Bayesian Spatial Following model, which estimates one's ideological position on a continuous scale by examining

\footnotetext{
${ }^{10}$ Tweets that had no tokens left after preprocessing were excluded.

${ }^{11}$ The findings are robust when using predictions produced by alternative models (see Appendix D).
} 
AFFECTIVE POLARIZATION ON SOCIAL MEDIA

elite accounts one follows. We then created an ideological extremity variable following the steps above $(M=0.33, S D=0.13)$.

In order to test RQ1, we also collected the number of likes and retweets using the Twitter API. Because these measures were skewed (e.g., some unknown politicians' tweets only had five likes while some of Donald Trump's tweets had thousands of likes), we transformed the data by taking the $\log$ of $(1+\mathrm{x})$.

In order to ascertain that the tested patterns are robust and not due to some confounders (e.g., users are more likely to engage with tweets about certain policies; the tweets by politicians with more followers are liked or reshared more frequently), our models included various stringent covariates. Topic of the tweet. We trained a Convolutional Neural Net (CNN) to predict the presence of topics from the Comparative Agendas Project in the tweets (see Appendix B). This variable was used as a control variable when testing $R Q 1$ as citizens may react differently to tweets discussing different topics. Additionally, the number of followers, the number of friends, and time of the day the tweet is posted may influence the way politicians discuss politics, the reach of their tweets, and consequently, the number of likes and retweets. We controlled for these factors when testing $H 2, H 3$, and $R Q 1$. Because the number of followers and number of friends were skewed, they were transformed by taking the $\log$ of $(1+x)$. Time of the day the tweet was posted was categorized into six levels (00:00-03:59, 04:00-07:59, 08:00-11:59, 12:0015:59, 16:00-19:59, 20:00-23:59).

\section{Results}

In total, 260,606 tweets, which were sent by 1008 accounts owned by 563 elites, discussed the two parties or their key politicians. 39\% of these tweets were from $2020,32 \%$ from 2019, 18\% from 2018, 10\% from 2017, and 1\% from 2016. 526 Democratic accounts sent 
AFFECTIVE POLARIZATION ON SOCIAL MEDIA

144,335 (55\%) tweets while 482 Republican accounts sent 116,271 (45\%) tweets. The majority of elite accounts (99\%) posted fewer than 1000 relevant tweets during the four years analyzed (see Appendix A).

Our first theoretical expectation was that political elites would predominantly exhibit negative partisanship when mentioning other parties and politicians in their social media posts, resulting in more posts criticizing the opposition than posts positive toward their own party. To test it, we compared the number of tweets negative toward the out-party to the number of tweets positive toward the in-party, as determined by our classifier. Politicians, as a whole, posted $19.14 \%$ more tweets positive toward the in-party than tweets negative toward the out-party (see Appendix A for details). Although not pre-registered, we additionally calculated the ratio of tweets positive toward the in-party to tweets negative toward the out-party for each account. The result shows that the majority of elite accounts $(67.13 \%)$ posted more tweets praising one's own side than tweets attacking the opposition. ${ }^{12}$ Thus, $\mathrm{H} 1$ is rejected..$^{13}$

Among all elite tweets discussing the two parties and key politicians, most were suggestive of affective polarization: $33 \%$ of the tweets were positive toward the in-party and $28 \%$ were negative toward the out-party. Almost a quarter were neutral toward either the in-party $(17 \%)$ or out-party $(6 \%)$. Only on rare occasions did politicians criticize the in-party $(6 \%$; e.g., David Perdue: "Like others who have run for president and failed, Mitt Romney has taken a stance that smacks of jealousy and resentment...”) and praise the out-party (10\%; e.g., Jim

\footnotetext{
${ }^{12} \mathrm{We}$ also tested this at the politician level by combining one's official and personal accounts. The result shows that $67.97 \%$ politicians posted more tweets praising one's own side than tweets attacking the opposition. It should be noted that 10 accounts (or one politician if combining official and personal accounts) did not post any tweets positive toward their own party and tweets negative toward the out-party, and were thus excluded.

${ }^{13} 12$ accounts owned by eight powerful politicians (i.e., Donald Trump, Mitt Romney, Mike Pence, Mitch McConnell, Joe Biden, Barack Obama, Hillary Clinton, and Nancy Pelosi) follow the same pattern: as a group, they posted 703 more tweets positive toward the in-party than tweets negative toward the out-party; individually, eight of these 12 accounts (or six out of eight politicians if we combine the official and personal accounts) posted more tweets positive toward the in-party than tweets negative toward the out-party.
} 
Langevin: “Congratulations to my good friend \& GOP colleague @CongressmanGT for his work on reauthorizing the \#PerkinsAct..."). ${ }^{14}$

$\mathrm{H} 2$ predicted that ideologically extreme politicians will exhibit stronger negative partisanship, sending tweets negative toward the opposing party, than the moderates. We first tested it at the tweet level by estimating two binary logistic regression models, predicting whether tweets mentioning the out-party were negative toward the out-party versus neutral or positive (tweets about the in-party were excluded). The first model tested the extremity of the political actor as determined by the DW-NOMINATE measure. We see a consistent pattern supporting our expectation. That is, controlling for the number of followers, the number of friends, and the time of the day the tweet was sent, a one-unit increase in DW-NOMINATE based ideological extremity, which was assessed on a normalized scale, leads to $754 \%$ increase in the odds of a tweet being negative toward the out-party (vs. positive or neutral toward the outparty). Clearly, the more extreme actors exhibit greater negative partisanship than those who are more moderate (see Appendix A for details).

To ascertain that this result holds when accounting for a distinct behavioral operationalization of ideological extremity (i.e., Barberá's Bayesian Spatial Following model), we estimated a parallel model. The results are nearly identical - for a one-unit increase in extremity on a normalized scale from moderate to most extreme, we find that the odds of a tweet being negative toward the out-party (vs. positive or neutral toward the out-party) increases by 966\% (see Appendix A for details). For example, @replucymcbath (owned by Rep. Lucy McBath), the most moderate account according to the Bayesian Spatial Following model based extremity, posted 20 tweets discussing the out-party (or its key politicians) and only five (25\%)

\footnotetext{
${ }^{14}$ Because the data are not evenly distributed across years, and only some politicians' tweets can be traced back to earlier years, we were unable to examine the overtime changes.
} 
AFFECTIVE POLARIZATION ON SOCIAL MEDIA

were negative. In contrast, @bryansteil (owned by Rep. Bryan Steil), one of the most extreme accounts, posted 50 tweets about the opposition and $30(60 \%)$ were negative.

We additionally tested $\mathrm{H} 2$ by examining the proportion of tweets negative toward the other side. For each account, we divided the number of tweets negative toward the out-party by the sum of tweets negative toward the out-party and positive toward the in-party (i.e., out-party negative/(out-party negative + in-party positive)) and regressed it on their ideological extremity, controlling for the number of followers and the number of friends. Results show that a one-unit increase in the normalized DW-NOMINATE based ideological extremity led to $22 \%$ increase in the proportion of tweets negative toward the out-party. For instance, Sen. Susan Collins, a famous moderate Republican, posted 3 tweets attacking the Democrats and 54 tweets praising her own party (5\%) using her official account @SenatorCollins; in contrast, Sen. Ted Cruz, a very conservative Republican, posted 374 and 43 tweets attacking the Democrats and 229 and 20 tweets praising his own party $(62 \% ; 68 \%)$ using his official account @sentedcruz and personal account @tedcruz respectively. A parallel model using measure of ideological extremity based on the Bayesian Spatial Following model had no significant influence on the proportion of tweets negative toward the out-party, but the effects were in the predicted direction (see Appendix A for details). In short, although there is one exception, H2 is supported in general. ${ }^{15}$

Furthermore, we tested whether negative partisanship varies by whether one is in the ruling party or the opposition party or - due to the timeframe of our data - whether one is a Democratic versus a Republican politician. To examine H3, according to which members of the opposition party (i.e., Democrats in our data) would exhibit stronger negative partisanship than political elites whose party is currently in power (i.e., Republicans), we estimated a binary

\footnotetext{
15 Those that do not have a DW-NOMINATE score or Barberá's ideological score (44 accounts/3069 tweets and 31 accounts/818 tweets respectively) were excluded from corresponding analysis.
} 
AFFECTIVE POLARIZATION ON SOCIAL MEDIA

logistic regression model predicting whether a politician's tweets were negative versus neutral or positive toward the outparty (tweets about the in-party were excluded). Consistent with H3, we find that the odds of being negative toward the out-party (vs. positive or neutral) are $23 \%$ higher for Democrats than Republicans. Also, the proportion of tweets negative toward the out-party (vs. positive toward the in-party) is $10 \%$ higher for Democratic politicians, compared to that of Republicans (see Appendix A for details). ${ }^{16}$

Before examining whether ordinary users engage most with messages representing positive or negative partisanship, we describe the engagement data. In the aggregate, the median number of likes on elite posts is 32 and the median number of retweets is 10 (mean likes $=1798$, mean retweets $=481)$. Tweets sent by Democratic politicians had a median of 34 likes and 11 retweets $($ mean likes $=1850$, mean retweets $=430)$ while tweets by Republicans had a median of 28 likes and 9 retweets $($ mean likes $=1735$, mean shares $=543)$. However, 82,565 (31.68\%) tweets received more than 100 likes and 51,859 (19.90\%) tweets got more than 100 retweets.

To address RQ1, we created a two-level "tweet type" variable by combining the target and sentiment (i.e., positive toward in-party vs. negative toward the out-party; other tweets were excluded). We find clear patterns of greater engagement with elite messages reflecting negative partisanship. Whereas tweets positive toward the in-party had a median of 29 likes and 9 retweets, elite tweets negative toward the out-party had 58 likes and 23 retweets (see Appendix A for details of other types of tweets). To assure that these patterns hold when accounting for various potential confounders, such as elite partisanship (i.e., elite tweets were liked and shared not only because of their party affiliation), the number of followers and friends, the topic of the

\footnotetext{
${ }^{16}$ As a pre-registered analysis, we also tested the effects of interaction between partisanship and ideological extremity on elite expression. Results show that ideologically extreme Republicans were more likely to be negative toward the out-party than moderate Republicans and that ideologically extreme Democrats were less likely to be negative toward the out-party than moderate Democrats. We present these results in Appendix A.
} 
AFFECTIVE POLARIZATION ON SOCIAL MEDIA

tweet, and the time of the day (i.e., tweets posted at late night might get fewer likes and retweets), we regressed the number of likes and retweets on tweet type respectively, with the above variables entered as covariates. It is clear that compared to tweets positive toward the inparty, those that are negative toward the out-party were liked and retweeted more even after accounting for these stringent covariates (see Appendix A for details). ${ }^{17}$

Although not pre-registered, we tested whether the number of likes and shares depends on elite partisanship and ideological extremity. Tweets attacking the opposition got more likes and shares if they were sent by Republican than Democratic politicians. In contrast, tweets praising the in-party were liked and shared more if they were posted by Democrats than Republicans. When it comes to elite ideological extremity, tweets positive toward the in-party were liked and shared more but tweets negative toward the out-party were liked and shared less when they were posted by ideological extremists, as indicated by Bayesian Spatial Following model based extremity score (but not DW-NOMINATE based extremity score; see Appendix A for details).

\section{Discussion}

Our project examined social media expressions of American political elites as well as users' engagement with politician's tweets side by side to offer systematic and comprehensive evidence on the effects of positive and negative partisanship on elites and ordinary users.

An exhaustive set of 564 US politicians was more likely to express their support toward their own party than to speak out against the opponents, indicating that the overall charge of partisanship for these elites is primarily positive when they discuss politics on social media. This robust pattern emerged when comparing the total number of tweets praising the in-party with that

\footnotetext{
${ }^{17}$ This pattern holds when tweets by Donald Trump and Joe Biden are removed. Besides, because we test at the tweet level, the finding is independent of the frequency that a politician tweets.
} 
AFFECTIVE POLARIZATION ON SOCIAL MEDIA

of tweets criticizing the out-party and calculating the proportion of elite accounts/elites that posted more tweets favoring the in-party than tweets expressing out-party negativity. Our evidence suggests that although many claim that negative partisanship is on the rise in the US (e.g., Abramowitz \& Webster, 2016; Iyengar et al., 2012) and that it is the driving force of biased political behaviors among ordinary citizens (Abramowitz \& Webster, 2016; Iyengar \& Krupenkin, 2018), positive partisanship still dominates elite behaviors, at least their political expressions on Twitter. Because we analyzed an exhaustive set of political elites and all their tweets mentioning the in- and out-party and their politicians and employed validated classifiers, we are confident that our results are a robust and accurate representation of political expressions by American politicians on Twitter.

These results counter the conventional wisdom that American politicians hate the outparty as much as, if not more than, they love the in-party. A possible explanation is that a minority of politicians who are highly vocal - and also influential - tend to be more negative toward the out-party. For instance, Donald Trump posted 569\% (174 vs. 26) and Joe Biden posted $343 \%$ (562 vs. 127) more tweets negative toward the out-party than tweets positive toward the in-party respectively. Additionally, if we simply use the number of followers as a rough indicator of readership (e.g., if a politician has one million followers and they post two tweets attacking the out-party, then we assume that these tweets were read two million times), overall, tweets attacking the out-party were read 32\% more than tweets praising the in-party, although the former was outnumbered by the latter. Given that the tweets negative toward the out-party were liked and shared more, as we detail below, they reach an even larger audience, creating the perception that American politicians hate the out-party more than they love the in- 
AFFECTIVE POLARIZATION ON SOCIAL MEDIA

party. We emphasize that this is not the case in our data and that these perceptions are (at least in part) attributable to the behaviors of ordinary users.

We also find that negative partisanship was stronger among those who were ideologically extreme than among the moderates; or in other words, the former group of politicians was most motivated to attack or criticize their out-party and toward prominent politicians from the opposite side. This finding was largely confirmed by two different measures of ideological extremity and is consistent with prior literature that ideological polarization contributes to negative feelings toward the opposing side (Abramowitz \& Webster, 2018; Webster \& Abramowitz, 2017). Because tweets negative toward the out-party posted by extreme politicians did not generate the greatest levels of engagement from ordinary users, this finding per se is not worrisome. Moreover, in line with previous evidence that threats to party identity strengthens negative partisanship (Amira et al., 2019), members of the party in the opposition - i.e., Democrats - showed greater negative partisanship than those of the ruling party. While it is the responsibility of the minority party to question and scrutinize the work of the ruling party, our finding may point to another issue in contemporary politics - the opposition just opposes everything from the ruling party, even when it is supported by most Americans.

Although elite expression is not as negative as expected, we should not be too optimistic. The exacerbating effects of extremity on negative partisanship implies that if the ideological division between the two parties widens, which is what we have witnessed in the past years (Newport \& Dugan, 2017), elite negative partisanship will be enhanced and may outstrip positive partisanship in opinion expressions, potentially inciting violence and enhancing undemocratic attitudes among the public (Kalmoe \& Mason, 2019). The fact that the strength of elites' negative partisanship depends on the level of extremity and on whether the party is in power 
AFFECTIVE POLARIZATION ON SOCIAL MEDIA

resonates with previous literature that the nature of affective polarization is not static but hinging on time and context (Amira et al., 2019; Bankert, 2020; Caruana et al., 2015; Lee et al., 2021). Future research should explore the strength of positive and negative partisanship in elite messages in other contexts. For example, compared to elite messages on social media, is elite communication as mediated through mainstream media more or less negative? We suspect that major news organizations, whether centrist or partisan, are most likely to pick up elite messages attacking the out-party because they generate the greatest attention. As such, the general perception that American elites are hostile toward the other side may partially be caused by the media's profit motive.

Another noteworthy finding is that negative partisanship drives ordinary citizens' liking and sharing of elite messages. That is, tweets that attacked the out-party got more likes and retweets than those that commended the in-party. Although this contradicts previous finding that individuals prefer to publish articles favoring the in-party than articles criticizing the other party (Amira et al., 2019), findings from experiments, in which participants are forced to see political messages and decide with which one to engage, may not accurately capture behavior in naturalistic settings. Our finding is consistent with the well-documented negativity bias (Rozin \& Royzman, 2001; Soroka \& McAdams, 2015), in that negativity attracts greater attention and generates stronger reactions than positivity (Soroka et al., 2019). Further, social media platforms are accused of taking advantage of this human bias by feeding people negative information. As a result, negative partisanship may be amplified through citizen-elite interactions: citizens reward politicians for attacking the opposition with more likes and shares, which may encourage politicians to express out-party hostility more fiercely; and more exposure to elite posts negative toward the out-party may, in turn, generate greater citizen engagement and enhance out-party 
AFFECTIVE POLARIZATION ON SOCIAL MEDIA

hostility among citizens. In fact, recent work finds that tweets sent by extreme in-party elites who are most negative toward the out-party - are also more likely to be shared (Wojcieszak et al., 2021).

When interpreting the results, several limitations need to be noted. First, as the data were collected before the 2020 election, it is unclear if these patterns would emerge after Joe Biden became the president. It is possible that Twitter suspending the account of Donald Trump may have changed the nature of online expression of American politicians. In a related vein, because Democrats were the opposition party in our data, we cannot rule out the possibility that the difference in elite expressions was influenced by partisanship and not only by the majority versus majority status of the politicians, as we theoretically argued. Future research should disentangle the effects of power status of the party and of partisanship.

We also acknowledge that we focused on tweets that explicitly mentioned the two parties and key politicians but did not account for policies, media organizations, or other factors potentially associated with a party. We did not include them because it is very challenging to construct a comprehensive and unbiased list of political topics discussed from 2016 to 2020 . Assessing how politicians talk about policies and other things is an important task for future work.

We do not know the partisan affiliations of those ordinary users who engaged with elite tweets. While it is reasonable to assume that most users share partisanship with those whose tweets they liked and shared (see Wojcieszak et al., 2021), we cannot systematically test this in our data. We were primarily interested in the more foundational evidence about elite expressions and citizen engagement, and the questions surrounding political homophily in these liking and retweeting networks are secondary. 
AFFECTIVE POLARIZATION ON SOCIAL MEDIA

Regardless, this work adds to our understanding of the driving force behind elite messages and citizen engagement with politicians' messages, demonstrating that political actors spend more efforts promoting their own party on social media than attacking the opposition, although they tend to attack the other side when they become more ideologically extreme and when they are not ruling. And yet, ordinary citizens engage disproportionately more with elite posts that are hostile toward the opposing party. These findings emphasize social media's huge and complicated impacts on democracy. 
AFFECTIVE POLARIZATION ON SOCIAL MEDIA

\section{References}

Abramowitz, A. I., \& Webster, S. (2016). The rise of negative partisanship and the nationalization of US elections in the 21st century. Electoral Studies, 41, 12-22.

Abramowitz, A. I., \& Webster, S. W. (2018). Negative partisanship: Why Americans dislike parties but behave like rabid partisans. Political Psychology, 39, 119-135.

Allport, G. W. (1954). The nature of prejudice. Addison-Wesley.

Amira, K., Wright, J. C., \& Goya-Tocchetto, D. (2019). In-Group Love Versus Out-Group Hate: Which Is More Important to Partisans and When? Political Behavior, 1-22.

Bakshy, E., Messing, S., \& Adamic, L. A. (2015). Exposure to ideologically diverse news and opinion on Facebook. Science, 348(6239), 1130-1132.

Bankert, A. (2020). Negative and Positive Partisanship in the 2016 US Presidential Elections. Political Behavior, 1-19.

Barberá, P. (2015). Birds of the same feather tweet together: Bayesian ideal point estimation using Twitter data. Political analysis, 23(1), 76-91.

Barberá, P., Casas, A., Nagler, J., Egan, P. J., Bonneau, R., Jost, J. T., \& Tucker, J. A. (2019). Who leads? Who follows? Measuring issue attention and agenda setting by legislators and the mass public using social media data. American Political Science Review, 113(4), 883-901.

Berry, J. M., \& Sobieraj, S. (2013). The outrage industry: Political opinion media and the new incivility. Oxford University Press.

Brewer, M. B. (1999). The psychology of prejudice: Ingroup love and outgroup hate? Journal of social issues, 55(3), 429-444. 
AFFECTIVE POLARIZATION ON SOCIAL MEDIA

Broockman, D., Kalla, J., \& Westwood, S. (2020). Does Affective Polarization Undermine Democratic Norms or Accountability? Maybe Not.

Brownstein, R. (2021, January 19). Trump leaves America at its most divided since the Civil War. CNN. https://www.cnn.com/2021/01/19/politics/trump-divided-america-civil$\underline{\text { war/index.html }}$

Campbell, A., Converse, P. E., Miller, W. E., \& Stokes, D. E. (1980). The american voter. University of Chicago Press.

Caruana, N. J., McGregor, R. M., \& Stephenson, L. B. (2015). The power of the dark side: Negative partisanship and political behaviour in Canada. Canadian Journal of Political Science/Revue canadienne de science politique, 771-789.

Cinelli, M., Morales, G. D. F., Galeazzi, A., Quattrociocchi, W., \& Starnini, M. (2021). The echo chamber effect on social media. Proceedings of the National Academy of Sciences, $118(9)$.

Druckman, J. N., Klar, S., Krupnikov, Y., Levendusky, M., \& Ryan, J. B. (2020). How Affective Polarization Shapes Americans' Political Beliefs: A Study of Response to the COVID-19 Pandemic. Journal of Experimental Political Science, 1-12.

Druckman, J. N., \& Levendusky, M. S. (2019). What do we measure when we measure affective polarization? Public Opinion Quarterly, 83(1), 114-122.

Druckman, J. N., Peterson, E., \& Slothuus, R. (2013). How elite partisan polarization affects public opinion formation. American Political Science Review, 57-79.

Finkel, E. J., Bail, C. A., Cikara, M., Ditto, P. H., Iyengar, S., Klar, S., Mason, L., McGrath, M. C., Nyhan, B., \& Rand, D. G. (2020). Political sectarianism in America. Science, $370(6516), 533-536$. 
AFFECTIVE POLARIZATION ON SOCIAL MEDIA

Geer, J. G. (2008). In defense of negativity: Attack ads in presidential campaigns. University of Chicago Press.

Geer, J. G. (2012). The news media and the rise of negativity in presidential campaigns. na.

Gelman, J., Wilson, S. L., \& Sanhueza Petrarca, C. (2020). Mixing messages: How candidates vary in their use of Twitter. Journal of Information Technology \& Politics, 1-15.

Hetherington, M. J., \& Rudolph, T. J. (2015). Why Washington won't work: Polarization, political trust, and the governing crisis (Vol. 104). University of Chicago Press.

Himelboim, I., Smith, M., \& Shneiderman, B. (2013). Tweeting apart: Applying network analysis to detect selective exposure clusters in Twitter. Communication methods and measures, 7(3-4), 195-223.

Iyengar, S. (2018). Media politics : A citizen's guide (Fourth, Ed.). WW Norton.

Iyengar, S., \& Krupenkin, M. (2018). The strengthening of partisan affect. Political Psychology, $39,201-218$.

Iyengar, S., Lelkes, Y., Levendusky, M., Malhotra, N., \& Westwood, S. J. (2019). The origins and consequences of affective polarization in the United States. Annual Review of Political Science, 22, 129-146.

Iyengar, S., Sood, G., \& Lelkes, Y. (2012). Affect, not ideology: a social identity perspective on polarization. Public Opinion Quarterly, 76(3), 405-431.

Iyengar, S., \& Westwood, S. J. (2015). Fear and loathing across party lines: New evidence on group polarization. American Journal of Political Science, 59(3), 690-707.

Jackson, R. A., \& Carsey, T. M. (2007). US Senate campaigns, negative advertising, and voter mobilization in the 1998 midterm election. Electoral Studies, 26(1), 180-195. 
AFFECTIVE POLARIZATION ON SOCIAL MEDIA

Kalmoe, N. P., \& Mason, L. (2019). Lethal mass partisanship: Prevalence, correlates, \& electoral contingencies. (Ed.),^(Eds.). National Capital Area Political Science Association American Politics Meeting.

Kingzette, J. (2021). Who Do You Loathe? Feelings toward Politicians vs. Ordinary People in the Opposing Party. Journal of Experimental Political Science, 8(1), 75-84.

Lau, R. R., \& Pomper, G. M. (2001). Negative campaigning by US Senate candidates. Party Politics, 7(1), 69-87.

Lau, R. R., \& Rovner, I. B. (2009). Negative campaigning. Annual Review of Political Science, $12,285-306$.

Lau, R. R., Sigelman, L., \& Rovner, I. B. (2007). The effects of negative political campaigns: A meta-analytic reassessment. The Journal of Politics, 69(4), 1176-1209.

Le, H. T., Boynton, G., Mejova, Y., Shafiq, Z., \& Srinivasan, P. (2017). Revisiting the american voter on twitter. (Ed.),^(Eds.). Proceedings of the 2017 CHI Conference on Human Factors in Computing Systems.

Lee, A. H.-Y., Lelkes, Y., Hawkins, C. B., \& Theodoridis, A. (2021). Not So Negative: The Nature of Partisan Attachment.

Lelkes, Y., \& Westwood, S. J. (2017). The limits of partisan prejudice. The Journal of Politics, $79(2), 485-501$

Levendusky, M. S. (2010). Clearer cues, more consistent voters: A benefit of elite polarization. Political Behavior, 32(1), 111-131.

Levendusky, M. S., \& Malhotra, N. (2016). Does media coverage of partisan polarization affect political attitudes? Political Communication, 33(2), 283-301. 
AFFECTIVE POLARIZATION ON SOCIAL MEDIA

Lewis, J. B., Poole, K., Rosenthal, H., Boche, A., Rudkin, A., \& Sonnet, L. (2020). Voteview: Congressional Roll-Call Votes Database.https://voteview.com/

Manchester, J. (2018, October 3). Analyst says US is most divided since Civil War. The Hill. https://hehill.com/hilltv/what-americas-thinking/409718-analyst-says-the-us-is-the-mostdivided-since-the-civl-war

McGregor, S. C. (2020). "Taking the Temperature of the Room” How Political Campaigns Use Social Media to Understand and Represent Public Opinion. Public Opinion Quarterly, 84(S1), 236-256.

Medeiros, M., \& Noël, A. (2014). The forgotten side of partisanship: Negative party identification in four Anglo-American democracies. Comparative Political Studies, $47(7), 1022-1046$.

Newport, F., \& Dugan, A. (2017). Partisan differences growing on a number of issues https://news.gallup.com/opinion/polling-matters/215210/partisan-differences-growingnumber-issues.aspx

Nicholson, S. P., Coe, C. M., Emory, J., \& Song, A. V. (2016). The politics of beauty: The effects of partisan bias on physical attractiveness. Political Behavior, 38(4), 883-898.

Pew. (2018a). Taking Sides on Facebook: How Congressional Outreach Changed Under President Trump. https://www.pewresearch.org/politics/2018/07/18/taking-sides-onfacebook-how-congressional-outreach-changed-under-president-trump/

Pew. (2018b). Why do people belong to a party? Negative views of the opposing party are a major factor. https://www.pewresearch.org/fact-tank/2018/03/29/why-do-people-belongto-a-party-negative-views-of-the-opposing-party-are-a-major-factor/ 
AFFECTIVE POLARIZATION ON SOCIAL MEDIA

Pew. (2021a). News Use Across Social Media Platforms in 2020.

https://www.journalism.org/2021/01/12/news-use-across-social-media-platforms-in$\underline{2020 /}$

Pew. (2021b). Though not especially productive in passing bills, the 116th Congress set new marks for social media use https://www.pewresearch.org/fact-tank/2021/01/25/thoughnot-especially-productive-in-passing-bills-the-116th-congress-set-new-marks-for-social$\underline{\text { media-use/ }}$

Poole, K. T., \& Rosenthal, H. (1997). Congress: A political-economic history of roll call voting. Oxford University Press.

Puglisi, R., \& Snyder Jr, J. M. (2011). Newspaper coverage of political scandals. The Journal of Politics, 73(3), 931-950.

Ridge, H. M. (2020). Enemy Mine: Negative Partisanship and Satisfaction with Democracy. Political Behavior, 1-25.

Rozin, P., \& Royzman, E. B. (2001). Negativity bias, negativity dominance, and contagion. Personality and social psychology review, 5(4), 296-320.

Soroka, S., Fournier, P., \& Nir, L. (2019). Cross-national evidence of a negativity bias in psychophysiological reactions to news. Proceedings of the National Academy of Sciences, 116(38), 18888-18892.

Soroka, S., \& McAdams, S. (2015). News, politics, and negativity. Political Communication, $32(1), 1-22$.

Theodoridis, A. (2019). Surprise! Most Republicans and Democrats identify more with their own party than against the other party. The Washington Post. 
AFFECTIVE POLARIZATION ON SOCIAL MEDIA

https://www.washingtonpost.com/politics/2019/07/25/surprise-most-republicansdemocrats-identify-more-with-their-own-party-than-against-other-party/

Webster, S. W. (2020). American Rage: How Anger Shapes Our Politics. Cambridge University Press.

Webster, S. W., \& Abramowitz, A. I. (2017). The ideological foundations of affective polarization in the US electorate. American Politics Research, 45(4), 621-647.

Wojcieszak, M., Casas, A., Yu, X., Nagler, J., \& Tucker, J. A. (2021). Echo chambers revisited: The (overwhelming) sharing of in-group politicians, pundits and media on Twitter.

Zhong, C.-B., Galinsky, A. D., \& Unzueta, M. M. (2008). Negational racial identity and presidential voting preferences. Journal of Experimental Social Psychology, 44(6), 15631566.

Zhong, C.-B., Phillips, K. W., Leonardelli, G. J., \& Galinsky, A. D. (2008). Negational categorization and intergroup behavior. Personality and Social Psychology Bulletin, 34(6), 793-806. 
Appendix A. Classifier performance and main results

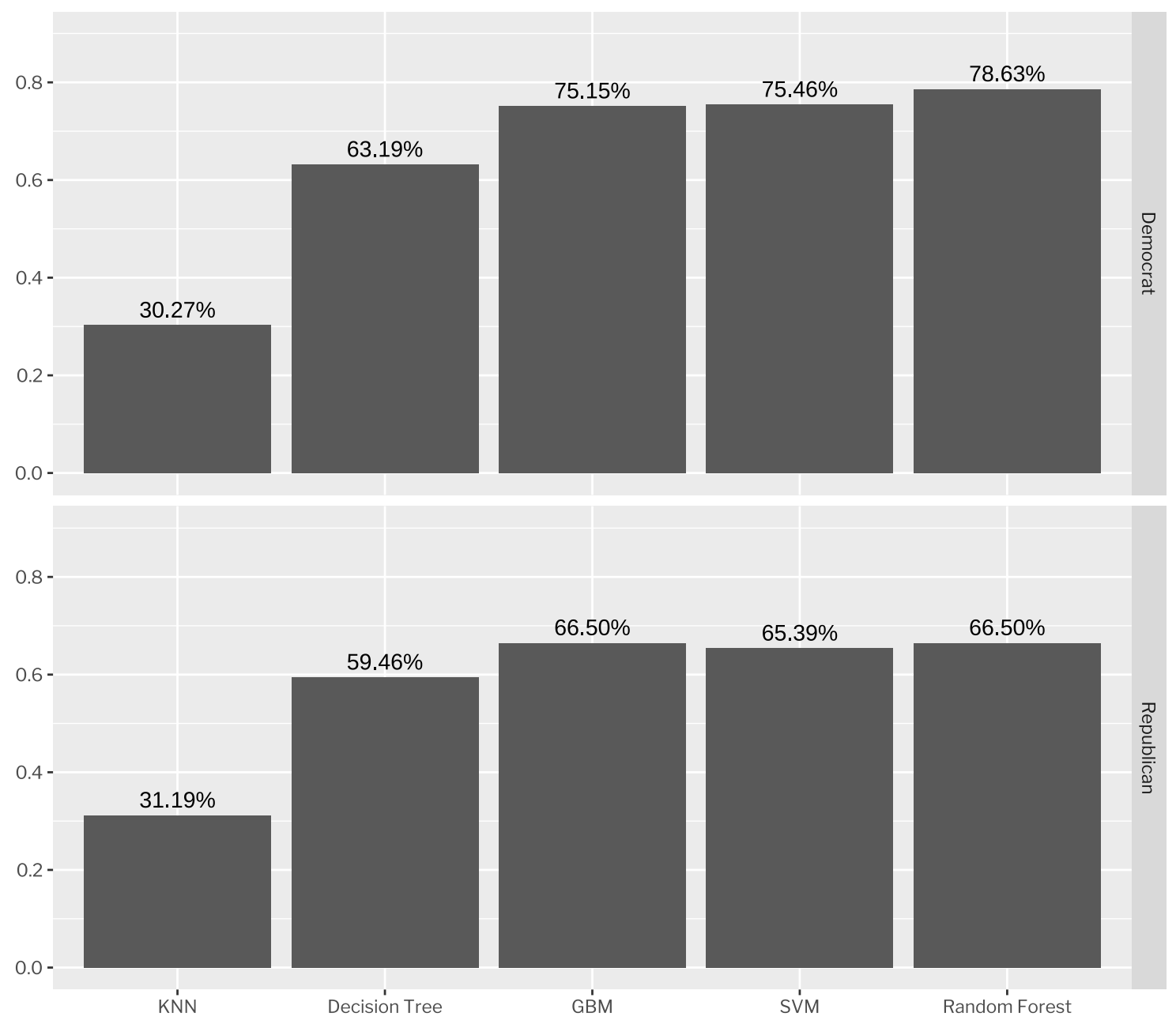

Appendix A. Figure 1: Overall out-of-sample accuracy of the 5 machine learning classifiers trained to predict attitudes of the tweets (top panel for tweets discussing the Democratic Party and bottom panel for tweets discussing the Republican Party). 


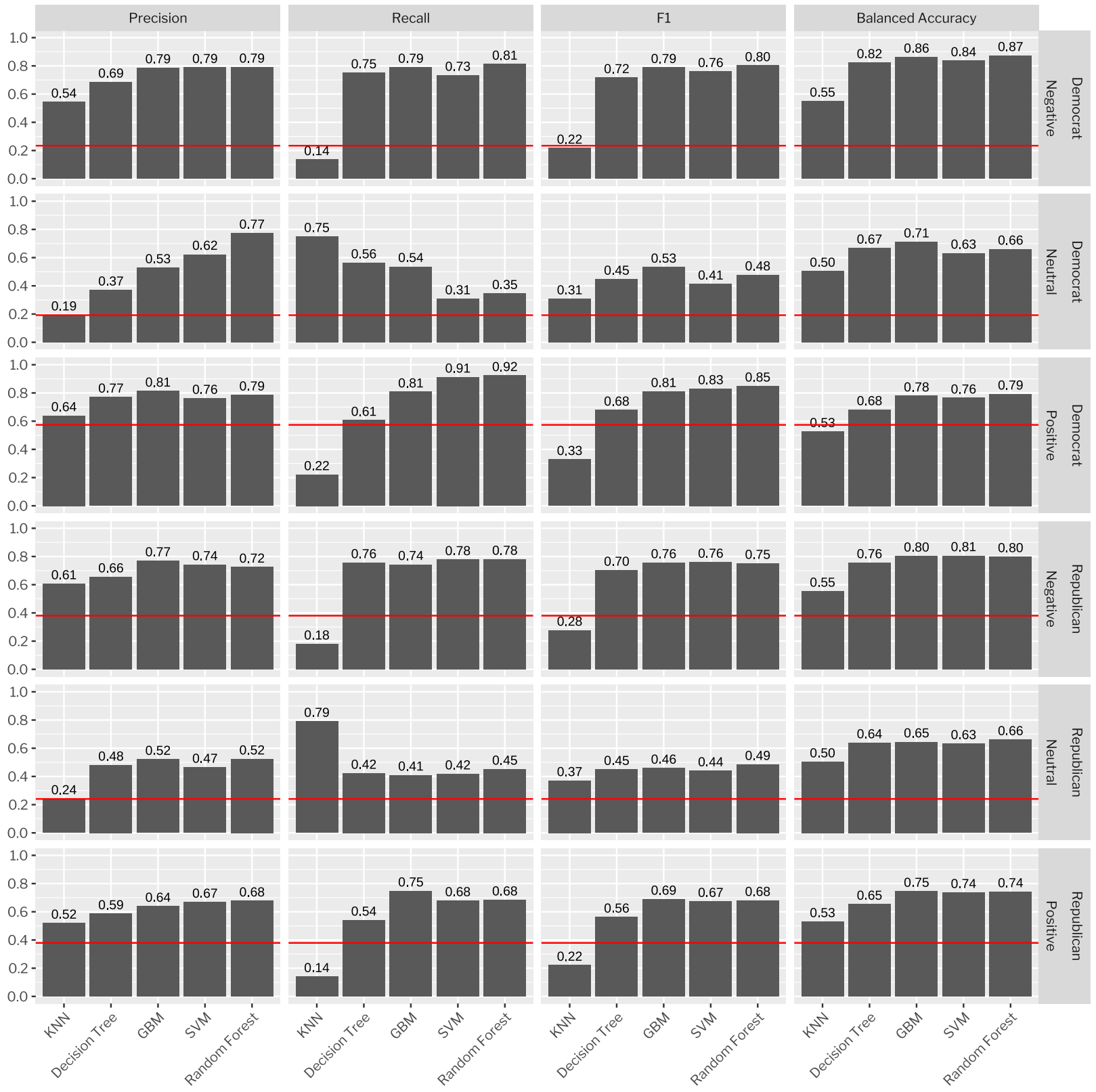

Appendix A. Figure 2: Target-class-level precision, recall and F1, and balanced accuracy for the 5 machine learning classifiers trained to predict attitudes of the tweets (top three panels for tweets discussing the Democratic Party and bottom three panels for tweets discussing the Republican Party). The horizontal red lines indicate the proportion of tweets coded as negative, neutral, and positive in the test set. 


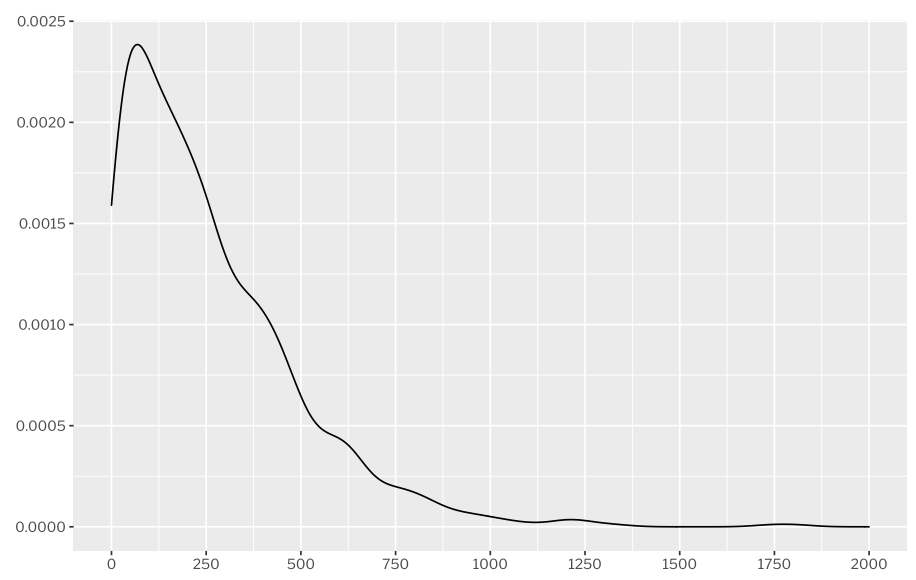

Appendix A. Figure 3: The distribution of accounts based on the number of tweets posted

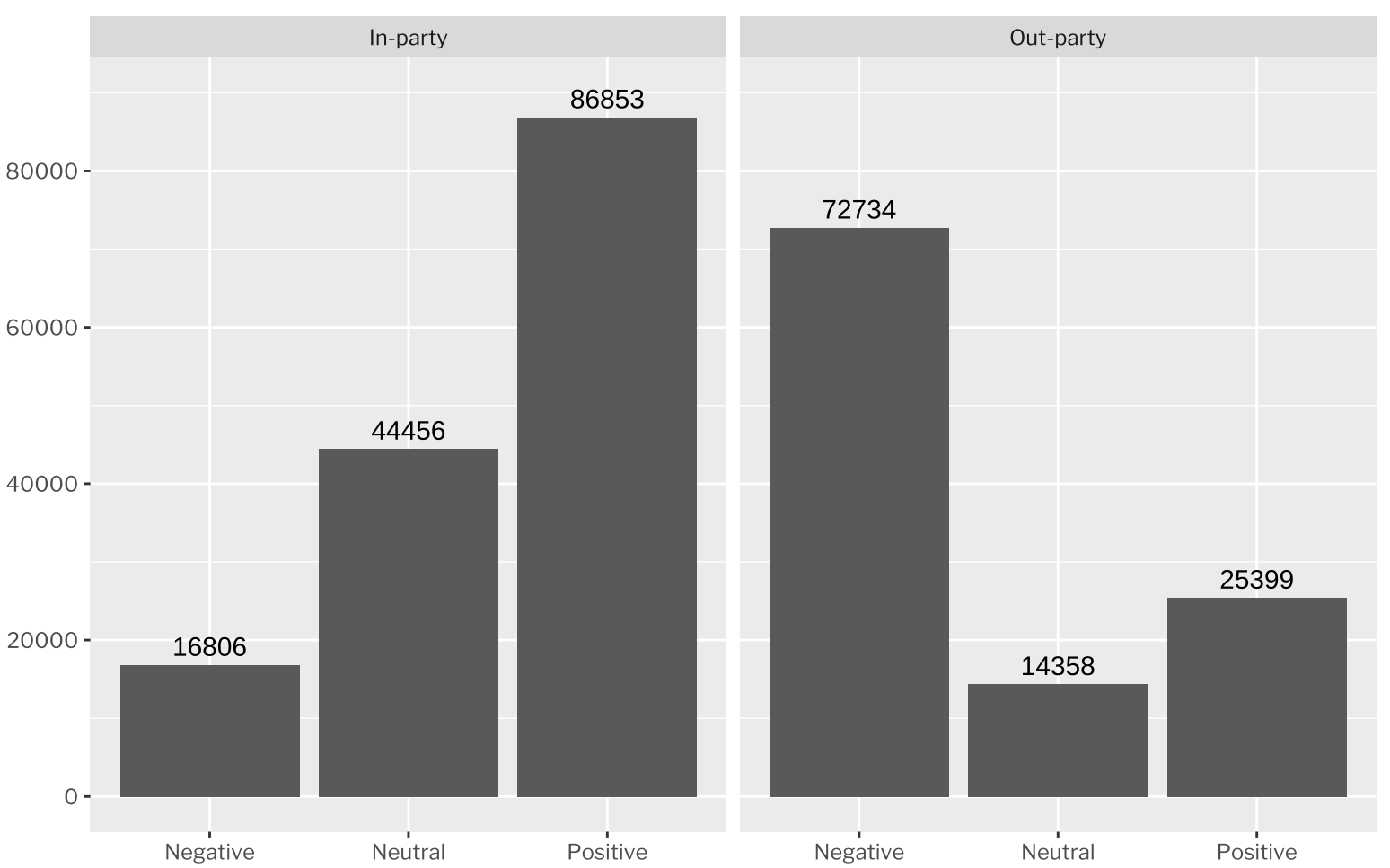

Appendix A. Figure 4: The number of tweets by target and attitude. 

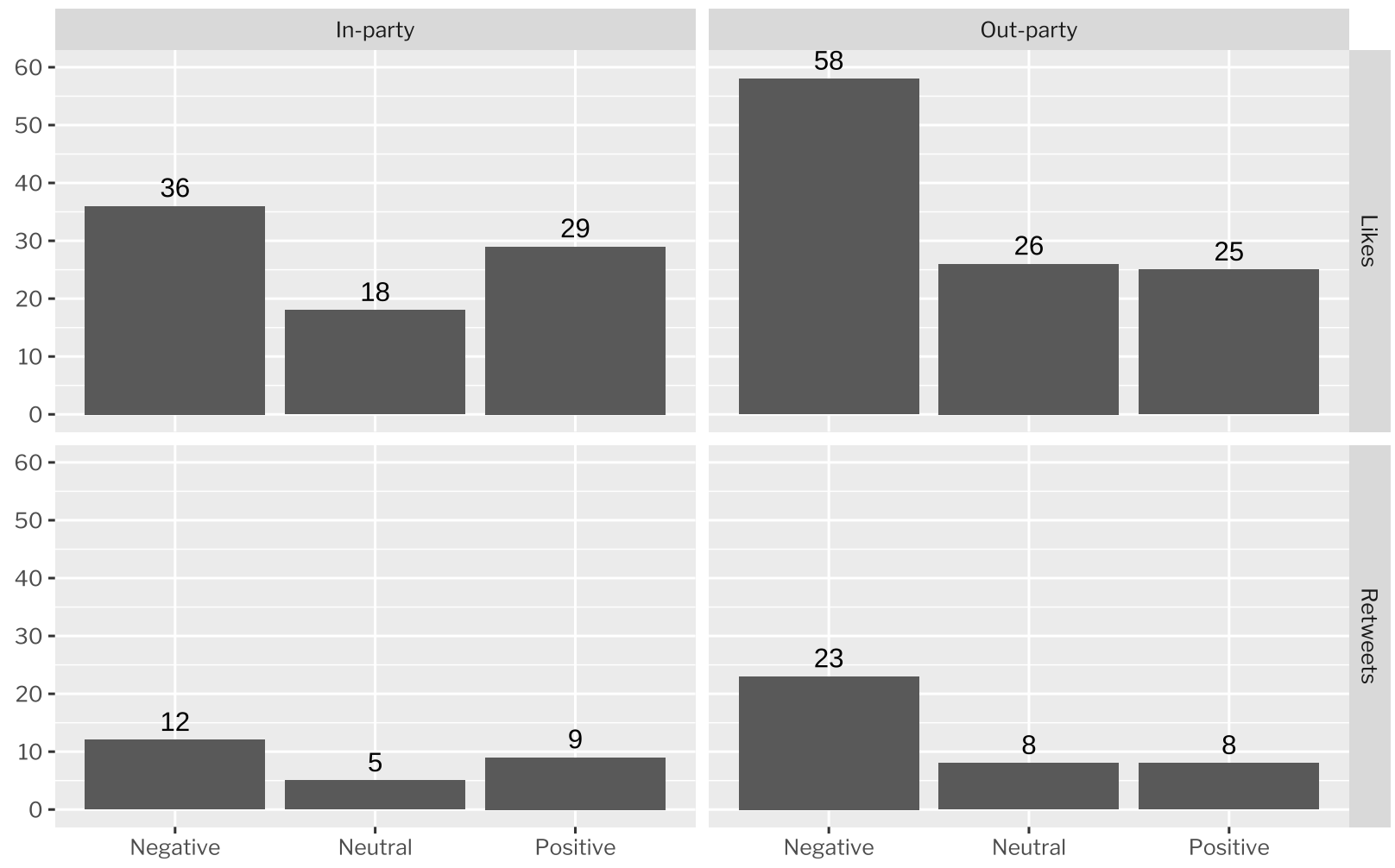

Appendix A. Figure 5: The median of likes and retweets by target and attitude. 
Appendix A. Table 1: The effects of ideological extremity on elite negative partisanship.

\begin{tabular}{|c|c|c|c|c|}
\hline & \multicolumn{4}{|c|}{ Elite Negative Partisanship } \\
\hline & \multicolumn{2}{|c|}{ Binary Logistic Regression } & \multicolumn{2}{|c|}{ OLS } \\
\hline & $\begin{array}{c}\text { DW- } \\
\text { NOMINATE }\end{array}$ & $\begin{array}{l}\text { Bayesian Spatial } \\
\text { Following Model }\end{array}$ & $\begin{array}{c}\text { DW- } \\
\text { NOMINATE }\end{array}$ & $\begin{array}{l}\text { Bayesian Spatial } \\
\text { Following Model }\end{array}$ \\
\hline Intercept & $-.85(.06) * * *$ & $-1.71(.06) * * *$ & $-.02(.05)$ & $-.01(.06)$ \\
\hline Ideo. Extremity & $2.14(.04) * * *$ & $2.37(.06) * * *$ & $.22(.04) * * *$ & $.07(.06)$ \\
\hline $\begin{array}{l}\text { Num. of } \\
\text { Followers }\end{array}$ & $.03(.00) * * *$ & $.08(.00) * * *$ & $.02(.00) * * *$ & $.02(.00) * * *$ \\
\hline $\begin{array}{l}\text { Num. of } \\
\text { Friends }\end{array}$ & $.04(.01) * * *$ & $.12(.01) * * *$ & $.01(.01) *$ & $.03(.01) * * *$ \\
\hline $\begin{array}{l}\text { Time (04:00 - } \\
07: 59)\end{array}$ & $-.47(.06) * * *$ & $-.48(.06) * * *$ & - & - \\
\hline $\begin{array}{l}\text { Time (08:00 - } \\
11: 59)\end{array}$ & $-1.01(.07) * * *$ & $-1.03(.07) * * *$ & - & - \\
\hline $\begin{array}{l}\text { Time (12:00 - } \\
15: 59)\end{array}$ & $-.16(.02) * * *$ & $-.16(.02) * * *$ & - & - \\
\hline $\begin{array}{l}\text { Time (16:00 - } \\
19: 59)\end{array}$ & $-.06(.02) * *$ & $-.06(.02) * *$ & - & - \\
\hline $\begin{array}{l}\text { Time (20:00 - } \\
23: 59)\end{array}$ & $-.13(.02) * * *$ & $-.14(.02) * * *$ & - & - \\
\hline$N$ & 109422 & 111673 & 954 & 967 \\
\hline$R^{2}$ & - & - & .092 & .059 \\
\hline$R^{2}$ (Nagelkerke) & .043 & .031 & - & - \\
\hline
\end{tabular}

Note: Cell entries are regression coefficients with associated standard errors in parentheses. ${ }^{*} p$ $<.05, * * p<.01, * * * p<.001$. 
Appendix A. Table 2: The effects of ruling/opposition status on elite negative partisanship

Elite Negative Partisanship

\begin{tabular}{lcc}
\hline & Binary Logistic Regression & OLS \\
\hline Intercept & $-.21(.05)^{* * *}$ & $.06(.04)$ \\
Status (Opposition) & $.21(.01)^{* * *}$ & $.10(.01)^{* * *}$ \\
Num. of Followers & $.05(.00)^{* * *}$ & $.01(.00)^{* * *}$ \\
Num. of Friends & $.03(.01)^{* * *}$ & $.02(.01)^{* * *}$ \\
Time (04:00 - 07:59) & $-.53(.06)^{* * *}$ & - \\
Time (08:00 - 11:59) & $-1.09(.07)^{* * *}$ & - \\
Time (12:00- 15:59) & $-.15(.02)^{* * *}$ & - \\
Time (16:00- 19:59) & $-.08(.02)^{* * *}$ & - \\
Time (20:00- 23:59) & $-.17(.02)^{* * *}$ & - \\
\hline$N$ & 112491 & 998 \\
$R^{2}$ & - & .101 \\
$R^{2}$ (Nagelkerke) & .011 & - \\
\hline
\end{tabular}

Note: Cell entries are regression coefficients with associated standard errors in parentheses. ${ }^{*} p$ $<.05, * * p<.01, * * * p<.001$.

Appendix A. Table 3: The effects of positive/negative partisanship on the number of likes and retweets

\begin{tabular}{lcc} 
& Likes & Retweets \\
\hline Intercept & $-6.16(.05)^{* * *}$ & $-6.34(.04)^{* * *}$ \\
Type (Negative Out-party) & $.43(.01)^{* * *}$ & $.62(.01)^{* * *}$ \\
Partisanship (Rep.) & $.31(.01)^{* * *}$ & $.33(.01)^{* * *}$ \\
Num. of Followers & $.94(.00)^{* * *}$ & $.85(.00)^{* * *}$ \\
Num. of Friends & $-.06(.00)^{* * *}$ & $-.05(.00)^{* * *}$ \\
Controlling for topic & Yes & Yes \\
Controlling for time & Yes & Yes \\
\hline$N$ & 159574 & 159574 \\
$R^{2}$ & .586 & .559 \\
\hline
\end{tabular}

Note: Cell entries are regression coefficients with associated standard errors in parentheses. 13 tweets were excluded because they had no predicted topics. ${ }^{*} p<.05$, ** $p<.01, * * * p<.001$. 
Appendix A. Table 4: The effects of interaction between partisanship and ideological extremity on elite negative partisanship.

\begin{tabular}{|c|c|c|c|c|}
\hline & \multicolumn{4}{|c|}{ Elite Negative Partisanship } \\
\hline & \multicolumn{2}{|c|}{ Binary Logistic Regression } & \multicolumn{2}{|c|}{ OLS } \\
\hline & DW-NOMINATE & $\begin{array}{l}\text { Bayesian Spatial } \\
\text { Following Model }\end{array}$ & DW-NOMINATE & $\begin{array}{l}\text { Bayesian Spatial } \\
\text { Following Model }\end{array}$ \\
\hline Intercept & $-.56(.06) * * *$ & $-1.41(.07) * * *$ & $.09(.05)$ & $.11(.06)$ \\
\hline Ideo. Extremity & $2.18(.06) * * *$ & $2.25(.06) * * *$ & $.19(.06) * *$ & $-.00(.08)$ \\
\hline Partisanship (Rep.) & $-.48(.04) * * *$ & $-.88(.05) * * *$ & $-.18(.04) * * *$ & $-.17(.04) * * *$ \\
\hline Num. of Followers & $.03(.00) * * *$ & $.08(.00) * * *$ & $.02(.00) * * *$ & $.02(.00) * * *$ \\
\hline Num. of Friends & $.01(.01)$ & $.10(.01) * * *$ & $.01(.01)$ & $.02(.01) * * *$ \\
\hline Time (04:00 - 07:59) & $-.48(.06) * * *$ & $-.50(.06) * * *$ & - & - \\
\hline Time (08:00 - 11:59) & $-.99(.07) * * *$ & $-1.02(.07) * * *$ & - & - \\
\hline Time $(12: 00-15: 59)$ & $-.14(.02) * * *$ & $-.13(.02) * * *$ & - & - \\
\hline Time $(16: 00-19: 59)$ & $-.06(.02) * *$ & $-.06(.02) * *$ & - & - \\
\hline Time $(20: 00-23: 59)$ & $-.12(.02) * * *$ & $-.14(.02) * * *$ & - & - \\
\hline $\begin{array}{l}\text { Ideo. Extremity } \times \\
\text { Partisanship (Rep.) }\end{array}$ & $.34(.08) * * *$ & $1.80(.15) * * *$ & $.17(.08) *$ & $.22(.11) *$ \\
\hline$N$ & 109422 & 111673 & 954 & 967 \\
\hline$R^{2}$ & - & - & .144 & .106 \\
\hline$R^{2}$ (Nagelkerke) & .049 & .038 & - & - \\
\hline
\end{tabular}


Appendix A. Table 5: The moderating effects of elite partisanship on the number of likes and retweets.

\begin{tabular}{lcc} 
& Likes & Retweets \\
\cline { 2 - 3 } Intercept & $-5.98(.05)^{* * *}$ & $-6.18(.04)^{* * *}$ \\
Type (Negative Out-party) & $.24(.01)^{* * *}$ & $.44(.01)^{* * *}$ \\
Partisanship (Rep.) & $.09(.01)^{* * *}$ & $.13(.01)^{* * *}$ \\
Num. of Followers & $.94(.00)^{* * *}$ & $.85(.00)^{* * *}$ \\
Num. of Friends & $-.06(.00)^{* * *}$ & $-.05(.00)^{* * *}$ \\
Controlling for topic & Yes & Yes \\
Controlling for time & Yes & Yes \\
Type (Negative Out-party) & $.49(.02)^{* * *}$ & $.45(.02)^{* * *}$ \\
$\quad$ Partisanship (Rep.) & & 159574 \\
\hline$N$ & 159574 & .561 \\
\hline$R^{2}$ & .588 & $131 w$ \\
\hline
\end{tabular}

Note: Cell entries are regression coefficients with associated standard errors in parentheses. 13 tweets were excluded because they had no predicted topics. ${ }^{*} p<.05,{ }^{* *} p<.01,{ }^{* * *} p<.001$.

Appendix A. Table 6: The moderating effects of ideological extremity on the number of likes and retweets.

\begin{tabular}{lcccc} 
& \multicolumn{2}{c}{ Likes } & \multicolumn{2}{c}{ Retweets } \\
\cline { 2 - 5 } & DW- & Bayesian Spatial & DW- & Bayesian Spatial \\
& NOMINATE & Following Model & NOMINATE & Following Model \\
\hline Intercept & $-6.39(.05)^{* * *}$ & $-6.58(.05)^{* * *}$ & $-6.63(.05)^{* * *}$ & $-6.87(.05)^{* * *}$ \\
Type (Negative Out-party) & $.42(.03)^{* * *}$ & $.60(.02)^{* * *}$ & $.64(.02)^{* * *}$ & $.77(.02)^{* * *}$ \\
Ideo. Extremity & $.36(.03)^{* * *}$ & $.79(.05)^{* * *}$ & $.62(.03) * * *$ & $.94(.04)^{* * *}$ \\
Partisanship (Rep.) & $.30(.01)^{* * *}$ & $.30(.01)^{* * *}$ & $.30(.01)^{* * *}$ & $.31(.01)^{* * *}$ \\
Num. of Followers & $.94(.00)^{* * *}$ & $.95(.00)^{* * *}$ & $.84(.00)^{* * *}$ & $.86(.00)^{* * *}$ \\
Num. of Friends & $-.06(.00)^{* * *}$ & $-.04(.00)^{* * *}$ & $-.05(.00)^{* * *}$ & $-.03(.00)^{* * *}$ \\
Controlling for topic & Yes & Yes & Yes & Yes \\
Controlling for time & Yes & Yes & Yes & Yes \\
Type (Negative Out-party) & $.04(.05)$ & $-.55(.06)^{* * *}$ & $-.04(.05)$ & $-.47(.06) * * *$ \\
$\times$ Ideo. Extremity & & & & \\
\hline$N$ & 153325 & 157422 & 153325 & 157422 \\
$R^{2}$ & .557 & .581 & .531 & .555 \\
\hline
\end{tabular}

Note: Cell entries are regression coefficients with associated standard errors in parentheses. For models using DWNOMINATE based extremity, 6262 tweets were excluded because they had no predicted topics or DW-

NOMINATE based extremity scores. For models using Bayesian Spatial Following Model based extremity, 2165 tweets were excluded because they had no predicted topics or Bayesian Spatial Following Model based extremity scores. $* p<.05, * * p<.01, * * * p<.001$. 
Appendix B. The topic classifier

In this section we explain how we automatically coded the topic of the content of the original tweets from elite accounts that we study. Given the large number of tweets, manual coding was not practical for the full corpus. Instead, we trained a machine learning model (a Convolutional Neural Net (CNN)) predicting whether each tweet discussed one of the 20 topics of the Comparative Agendas Project (CAP) (Baumgartner \& Jones, 2010), ${ }^{1}$ a comprehensive and widely used classification for studying political agendas, plus a non-policy-issue category reserved for tweets that did not address any substantive policy area, such as tweets commemorating holidays. ${ }^{2}$ Similar to Kim (2014), we trained a three-layer CNN. Figure 1 illustrates the architecture used to identify CAP-topics. We next describe our two main model architectures, and then proceed to describe in detail our training data-sets and validation scheme. This model was originally trained and validated for another of our projects in which we needed to predict the topic of tweets sent by state legislators in the United States around the same time period, so we are confident that it does a good job at predicting the topic of tweets sent by political elites.

First, we represented each word in a given sentence as a 300-dimension word-embedding (a vector that ideally represents an integration of each word's meaning and context/position in the text as dense features for further analysis) (Terechshenko et al., 2020). We obtained the models used to produce word-embeddings by finetuning a pretrained Word2Vec model for an additional 10 epochs (Mikolov et al., 2013), to which we had first added all unique new vocabulary present

\footnotetext{
${ }^{1}$ We excluded Culture topics from the 21 topics of the CAP codebook because in initial tests we saw very low numbers of tweets about this topic and the topic was not very relevant for the analysis carried out here.

${ }^{2}$ See Table 3 for a list of topics.
} 
in our training datasets as well as in the tweets to which we wanted to apply the resulting model. ${ }^{3}$ This results in a three-dimensional matrix $(n \times k \times d)$ that is used as our primary model input, where $n$ is the maximum word length for all training documents, $k$ is the size of the embedding (300), and $d$ is the number of documents to pass through to the CNN.

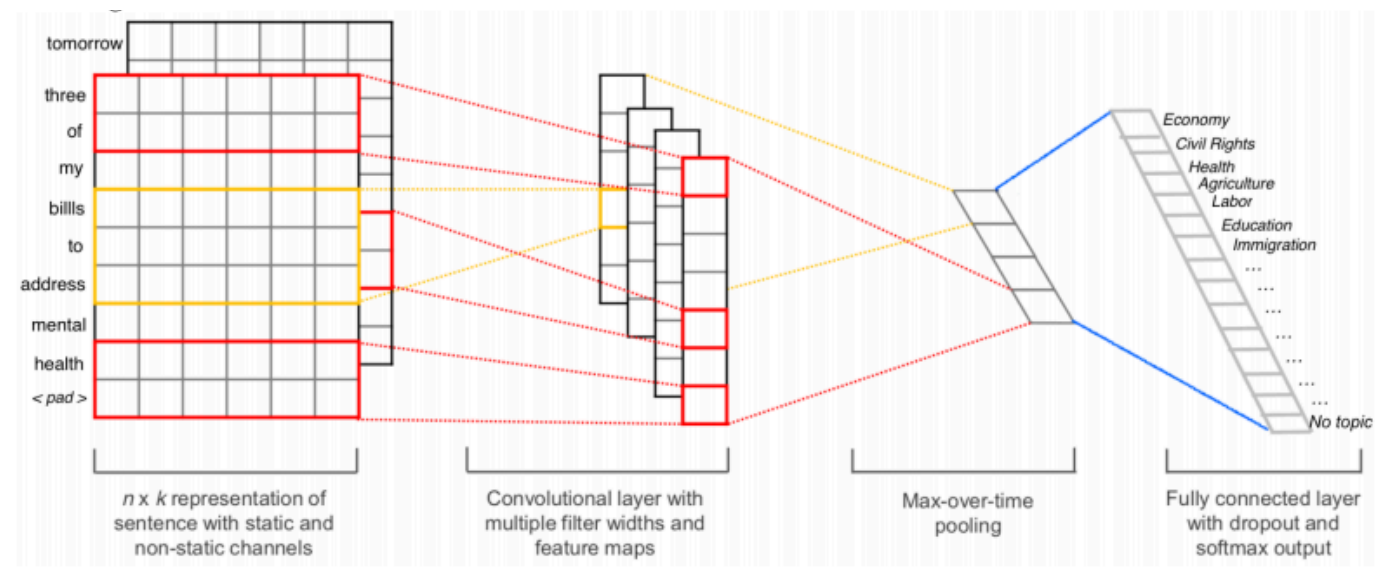

Appendix B. Figure 1: Architecture of the Convolutional Neural Net predicting the policy topics discussed in tweets by state legislators.

The CNN that comprises our second model (the model used to classify the CAP topic) has three convolutional layers of different sizes, each processing 3-, 4-, and 5-word embeddings at a time, and so producing hidden layers of different sizes. These hidden layers are joined into a single vector for each document by max-pooling the weights in each word-vector. The last stage of the $\mathrm{CNN}$ is comprised of a fully connected layer mapping the previous max-pooled vector to the 21 CAP issue classes (20 policy areas plus the "non-policy/not-relevant" class). We employ a

\footnotetext{
${ }^{3}$ We used the python Gensim word2vec model and methods, and GloVe pretrained embeddings: Common Crawl (42B tokens, $1.9 \mathrm{M}$ vocab, uncased, $300 \mathrm{~d}$ vectors, $1.75 \mathrm{~GB}$ download).
} 
cross-entropy loss function; gradient optimization is performed via adaptive moment estimation (Kingma \& Ba, 2015). We use a batch size of 64 for training the model.

We trained the model with various datasets, assessed the out-of-sample accuracy of each model-dataset pair and selected the best performing model-data pairing to generate topic predictions for tweets sent by political elites in 2018: state legislators from the United States. In our training datasets, each observation (document or tweet) has been coded as belonging to one (mutually exclusive) topic category (or the no-topic one).

We used four datasets, described in Table 1. The first one is composed of publicly available data, the second one comes from the replication material of a published study, and the final two have been created/annotated by us for the purpose of this and other studies. In the first dataset (A) we combined all available CAP-labeled datasets for the United States available in the CAP website (789,004 observations in total). The second dataset (B) is comprised of 45,394 tweets from Senators who served during the 113th Congress and that were labeled by (Russell, 2018). The third set (C) consists of 18,088 tweets sent by media accounts and followers of state legislators that we coded according to the CAP classification. The fourth dataset (D) consists of 3,368 tweets sent by the state legislators that we also annotated. ${ }^{4}$ We trained the same CNN model nine times using the following data combinations, with the goal of taking advantage of transfer learning and training more accurate models than simply training the model with the tweets from state legislators that we had coded (so only set D): (1) only set A, (2) only set D, (3) set $\mathrm{A}$ and set D, (4) set D and a small sample of set A (1,300 observations), (5) set D and a

\footnotetext{
${ }^{4}$ A total of six coders (research assistants) participated in the annotation of sets $\mathrm{C}$ and D. Two coders annotated the tweets sent by media accounts (C.a): 89\% agreement and 0.7 Cohen's Kappa. Two other coders annotated the tweets sent by followers of state legislators (C.b): 91\% agreement and 0.77 Cohen's Kappa. And finally, a different pair of coders annotated the tweets sent by state legislators (D): $87.1 \%$ agreement and 0.74 Cohen's Kappa.
} 
smaller sample of set A (650 observations), (6) set D and set B, (7) set D and a small sample of set B (1,300 tweets), (8) set D and a smaller sample of set B (650 tweets), (9) set D and set C.

Appendix B. Table 1: Public datasets coded using the CAP 21-issue classification, used for training and testing a classifier predicting Policy Issues in tweets from state legislators.

\begin{tabular}{llll}
\hline Set & Dataset & Time & $\mathrm{N}$ \\
\hline & Congressional Quarterly Almanac & $1948-2015$ & 14,444 \\
& New York Times Front Page & $1996-2006$ & 31,034 \\
& New York Times Index & $1946-2014$ & 54,578 \\
& Congressional Bills & $1947-2016$ & 463,762 \\
& Congressional Hearings & $1946-2015$ & 97,593 \\
& Public Law Titles & $1948-2011$ & 33,644 \\
A & Public Laws & $1948-2017$ & 20,928 \\
& Executive Orders & $1945-2017$ & 4,294 \\
& Presidential Veto Rhetoric & $1985-2016$ & 1,618 \\
& State of the Union Speeches & $1946-2018$ & 22,289 \\
& Democratic Party Platform & $1948-2016$ & 15,953 \\
& Republican Party Platform & $1948-2016$ & 19,836 \\
& Supreme Court Cases & $1944-2009$ & 9,031 \\
\hline B & Tweets sent by Senators 113th Congress & $2013-2015$ & 45,394 \\
\hline C & Tweets sent by media accounts & 2018 & 8,802 \\
& Tweets sent by followers of state legislators & 2018 & 9,286 \\
\hline D & Tweets sent by state legislators & 2018 & 3,368 \\
\hline & Total & $1944-2018$ & 855,854
\end{tabular}

Appendix B. Table 2: Out of sample accuracy of the nine versions of the CNN model we trained predicting the political topics of the Comparative Agendas Project.

\begin{tabular}{|l|l|l|}
\hline Model Version & Test Accuracy & Test Accuracy Policy Tweets \\
\hline (6) set D and B & 0.78 & 0.79 \\
\hline (1) set A & 0.73 & 0.73 \\
\hline (3) set D and A & 0.73 & 0.73 \\
\hline (9) set D and C & 0.77 & 0.49 \\
\hline (7) set D and small B & 0.56 & 0.36 \\
\hline (4) set D and small A & 0.55 & 0.32 \\
\hline (8) set D and smaller B & 0.57 & 0.29 \\
\hline (5) set D and smaller A & 0.56 & 0.28 \\
\hline (2) set D & 0.60 & 0.26 \\
\hline
\end{tabular}


To assess the performance of these nine versions of the model we split the data used in each case into a train and test set. In Table 2 we report the accuracy of the nine versions of the model we trained (based on 3-fold cross-validation), based on held-out test sets. We assess the test accuracy when predicting all tweets in the test split (Test Accuracy), and also when only predicting the tweets coded as being about one of the policy areas, so after excluding the nopolicy tweets (Test accuracy policy tweets). The tweets not related to any policy area represented a large part of the tweets we coded from state legislators (set D) and we wanted to make sure that our model did well at both distinguishing overall policy relevance and at distinguishing between policy areas.

Appendix B. Table 3: Class accuracy and f-score for the best performing model.

\begin{tabular}{llll}
\hline Policy Area & Class Proportion & Test Accuracy & Test F-score \\
\hline No Policy & 0.48 & 0.74 & 0.82 \\
Govt. Operations & 0.13 & 0.81 & 0.75 \\
Health & 0.06 & 0.80 & 0.73 \\
Economy & 0.05 & 0.74 & 0.76 \\
Education & 0.03 & 0.83 & 0.67 \\
Civil Rights & 0.03 & 0.69 & 0.58 \\
Housing & 0.02 & 0.36 & 0.46 \\
Environment & 0.02 & 0.58 & 0.61 \\
Transportation & 0.02 & 0.73 & 0.68 \\
Agriculture & 0.02 & 0.93 & 0.72 \\
Energy & 0.02 & 0.83 & 0.70 \\
Social Welfare & 0.02 & 0.53 & 0.61 \\
Law \& Crime & 0.02 & 0.67 & 0.48 \\
Intl. Affairs & 0.01 & 0.71 & 0.63 \\
Immigration & 0.01 & 0.92 & 0.92 \\
Public Lands & 0.01 & 0.67 & 0.63 \\
Labor & 0.01 & 0.70 & 0.56 \\
Domestic Commerce & 0.01 & 0.75 & 0.45 \\
Technology & 0.01 & 0.38 & 0.50 \\
Defense & 0.00 & 0.75 & 0.35
\end{tabular}


The model trained with the coded tweets by state legislators plus the coded tweets sent by Senators of the 113th Congress returned the best (and very satisfactory) results when predicting out of sample the topic of tweets from state legislators. We hence used this model to generate topic predictions for the tweets sent by the elite accounts in the paper. The test accuracy in both cases is close to $80 \%$ (very high given that the model is predicting 21 topic classes, and that topic overlap is possible in the training set). In Table 3 we show that the accuracy and f-score (based on the held-out test sets) is very high for all the topic classes, despite most of them being rarely discussed.

To assess the face validity of the model, in Table 4 we show the top distinctive text features of the tweets predicted to be about each topic. Reassuringly, the top features seem to be relevant to each topic.

Appendix B. Table 4: Top distinctive features of tweets predicted by the CNN to be about each topic or policy area.

\begin{tabular}{|c|c|}
\hline Topic & Top Features \\
\hline No Policy & $\begin{array}{l}\text { thank, great, all, today, so, day, me, one, happy, m, good, time, thanks, } \\
\text { join }\end{array}$ \\
\hline Govt. Operations & $\begin{array}{l}\text { vote, election, today, day, state, voting, primary, early, all, house, time, } \\
\text { democratic, people }\end{array}$ \\
\hline Health & $\begin{array}{l}\text { health, care, maternal, mental, new, day, flu, healthcare, work, get, state, } \\
\text { medicaid, mortality, all }\end{array}$ \\
\hline Economy & tax, taxes, property, budget, economy, state, tariffs, need, spending \\
\hline Education & $\begin{array}{l}\text { school, students, education, public, schools, teachers, state, finance, } \\
\text { college, high, teacher, funding, kids }\end{array}$ \\
\hline Civil Rights & $\begin{array}{l}\text { women, rights, scotus, redistricting, day, voter, case, join, people, court, } \\
\text { families }\end{array}$ \\
\hline Housing & $\begin{array}{l}\text { housing, affordable, hearing, association, austin, citys, gentrification, } \\
\text { losaltos, meeting, neighborhood, policy, access, aff, affairs }\end{array}$ \\
\hline Environment & $\begin{array}{l}\text { water, climate, change, earthday, right, air, cleanup, lake, nasa, san, } \\
\text { brownsville, great, mars }\end{array}$ \\
\hline tation & transportation, nasa, outhwestair, airlines, future, hearing, bus, get \\
\hline Agric & $\begin{array}{l}\text { food, farm, farmers, agriculture, taking, agricultural, bureau, campus, } \\
\text { farming, learning }\end{array}$ \\
\hline
\end{tabular}




\begin{tabular}{|c|c|}
\hline Energy & $\begin{array}{l}\text { energy, gas, oil, solar, texasoilnews, oilandgas, texasoil, txenergy, back, } \\
\text { coal, committee, cpsenergy, nasa, natural, next }\end{array}$ \\
\hline Social Welfare & $\begin{array}{l}\text { food, safoodbank, snap, hunger, meals, help, million,free, program, } \\
\text { children, kids, nutritious, summer }\end{array}$ \\
\hline Law \& Crime & $\begin{array}{l}\text { children, gun, violence, families, law, parents, sexual, separated, thank, } \\
\text { guns, people, child, school, community }\end{array}$ \\
\hline Intl. Affairs & $\begin{array}{l}\text { russia, russian, putin, right, now, trumps, world, american, dead, peace, } \\
\text { people, says }\end{array}$ \\
\hline Immigration & $\begin{array}{l}\text { daca, children, border, immigration, immigrants, immigrant, families, } \\
\text { dreamers, policy, parents, detention, migrant, family, stand, trumps }\end{array}$ \\
\hline Public Lands & $\begin{array}{l}\text { park, state, fire, during, public, thank, wildlife, beautiful, city, } \\
\text { confederate, contained, discussion, grand, heritage, history, land }\end{array}$ \\
\hline Labor & $\begin{array}{l}\text { job, workers, fair, jobs, community, employees, need, work, workforce, } \\
\text { working, youth, according, better }\end{array}$ \\
\hline Domestic & harvey, flooding, community, business, small, city, need, local, \\
\hline Com & businesses, hurricane, many, disaster, state, flood \\
\hline Technology & $\begin{array}{l}\text { nasa, space, station, mission, astronaut, international, students, media, } \\
\text { crew, launch, satellite, astronauts, awards, contract, earth, internet }\end{array}$ \\
\hline Defense & $\begin{array}{l}\text { military, veterans, war, one, day, women, state, families, honor, veteran, } \\
\text { friend }\end{array}$ \\
\hline Foreign Trade & $\begin{array}{l}\text { trade, trumps, war, abandons, barrel, beijing, billion, breath, canada, } \\
\text { chinese, cover, currently, deals, economy }\end{array}$ \\
\hline
\end{tabular}

\section{References}

Baumgartner, Frank R \& Bryan D Jones. Agendas and instability in American politics. University of Chicago Press, 2010.

Kim, Yoon. Convolutional neural networks for sentence classification. CoRR, abs/1408.5882, 2014.

Kingma, Diederik P. \& Jimmy Ba. Adam: A method for stochastic optimization. In $3 r d$ International 17 Conference on Learning Representations, ICLR 2015, San Diego, CA, USA, May 7-9, 2015, Conference Track Proceedings, 2015.

Mikolov, Tomas, Kai Chen, Greg Corrado, \& Jeffrey Dean. Efficient estimation of word representations in vector space. In 1st International Conference on Learning Representations, ICLR 2013, Scottsdale, Arizona, USA, May 2-4, 2013, Workshop Track Proceedings, 2013.

Russell, Annelise. Us senators on twitter: Asymmetric party rhetoric in 140 characters. American Politics Research, 46(4):695-723, 2018.

Terechshenko, Zhanna, Fridolin Linder, Vishakh Padmakumar, Fengyuan Liu, Jonathan Nagler, Joshua A. Tucker, \& Richard Bonneau. A comparison of methods in political science text classification: Transfer learning language models for politics. Presented at the XXXVII PolMeth Annual Meeting, 2020. 
Appendix C. Deviations from the preregistration

We rescaled the two ideological extremity scores because it would make the comparisons more straightforward. There are two typos in the analysis plan of $\mathrm{H} 2$ and H3: instead of "tweets about the inparty will be included," it should be "tweets about the inparty will be excluded." This can also be inferred from the context. When testing $\mathrm{H} 2$ and $\mathrm{H} 3$ using the OLS regression, the time of the day the tweet was sent was not entered as a covariate because we tested at the politician level not the tweet level. In testing RQ1, we created a two-level "tweet type" variable by combining the target and sentiment (i.e., positive toward in-party vs. negative toward the outparty; other tweets were excluded) rather than interacting the target and attitude to make the result easier to interpret. Additionally, in the preregistration, we stated that we would test RQ1 (which was mistakenly written as H4 in the preregistration) on Donald Trump and Joe Biden respectively. Results show that for Trump, tweets negative toward the out-party were liked and shared more than tweets positive toward the in-party and that for Biden, tweets negative toward the out-party were shared (but not liked) more than tweets positive toward the in-party. 
Appendix D. Results using predictions produced by SVM models
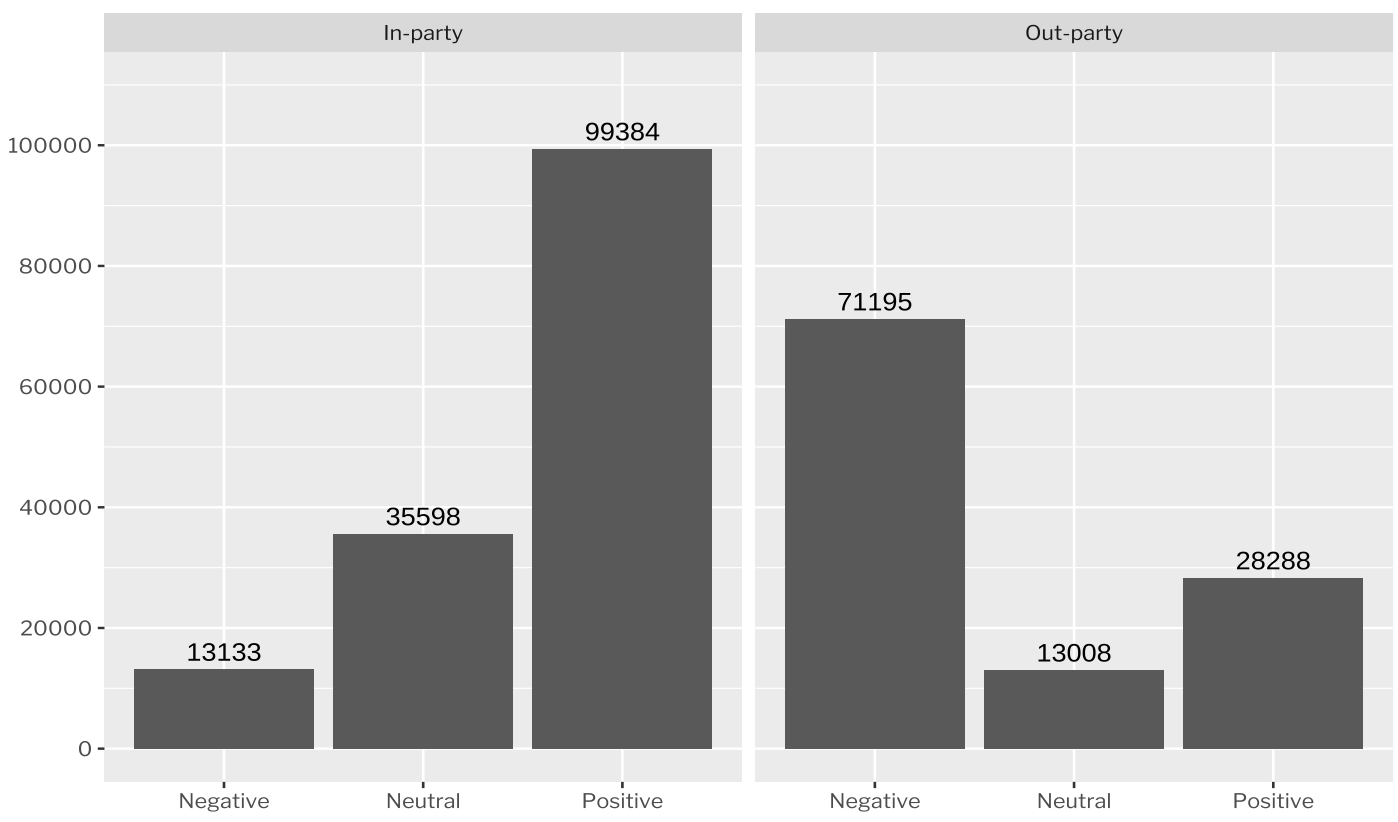

Appendix D. Figure 1: The number of tweets by target and attitude (SVM).
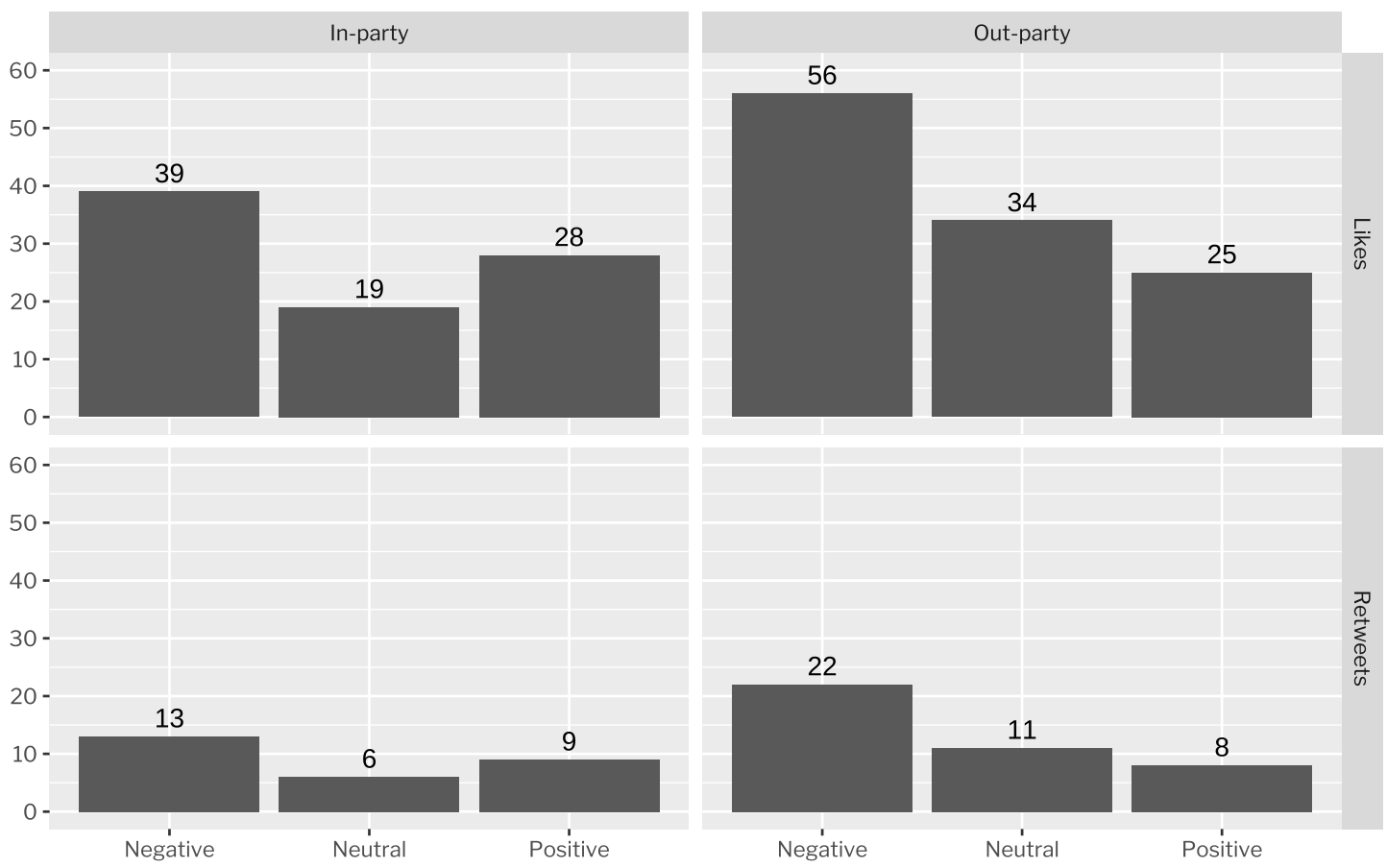

Appendix D. Figure 2: The median of likes and retweets by target and attitude (SVM). 
Appendix D. Table 1: The effects of ideological extremity on elite negative partisanship (SVM).

\begin{tabular}{|c|c|c|c|c|}
\hline & \multicolumn{4}{|c|}{ Elite Negative Partisanship } \\
\hline & \multicolumn{2}{|c|}{ Binary Logistic Regression } & \multicolumn{2}{|c|}{ OLS } \\
\hline & $\begin{array}{c}\text { DW- } \\
\text { NOMINATE }\end{array}$ & $\begin{array}{l}\text { Bayesian Spatial } \\
\text { Following Model }\end{array}$ & $\begin{array}{c}\text { DW- } \\
\text { NOMINATE }\end{array}$ & $\begin{array}{l}\text { Bayesian Spatial } \\
\text { Following Model }\end{array}$ \\
\hline Intercept & $-.98(.05) * * *$ & $-1.76(.06) * * *$ & $-.06(.04)$ & $-.06(.05)$ \\
\hline Ideo. Extremity & $2.15(.04) * * *$ & $2.24(.05) * * *$ & $.23(.04) * * *$ & $.09(.05)$ \\
\hline $\begin{array}{l}\text { Num. of } \\
\text { Followers }\end{array}$ & $.02(.00) * * *$ & $.06(.00) * * *$ & $.03(.00) * * *$ & $.02(.00) * * *$ \\
\hline Num. of Friends & $.06(.01) * * *$ & $.14(.01) * * *$ & .01 (.01) & $.03(.01) * * *$ \\
\hline $\begin{array}{l}\text { Time }(04: 00 \text { - } \\
07: 59)\end{array}$ & $-.39(.06) * * *$ & $-.40(.06) * * *$ & - & - \\
\hline $\begin{array}{l}\text { Time }(08: 00 \text { - } \\
11: 59)\end{array}$ & $-1.00(.07) * * *$ & $-1.05(.07) * * *$ & - & - \\
\hline $\begin{array}{l}\text { Time }(12: 00 \text { - } \\
15: 59)\end{array}$ & $-.16(.02) * * *$ & $-.15(.02) * * *$ & - & - \\
\hline $\begin{array}{l}\text { Time (16:00 - } \\
\text { 19:59) }\end{array}$ & $-.05(.02) *$ & $-.05(.02) *$ & - & - \\
\hline $\begin{array}{l}\text { Time }(20: 00 \text { - } \\
\text { 23:59) }\end{array}$ & $-.13(.02) * * *$ & $-.14(.02) * * *$ & - & - \\
\hline$N$ & 109422 & 111673 & 959 & 972 \\
\hline$R^{2}$ & - & - & 104 & .069 \\
\hline$R^{2}$ (Nagelkerke) & .044 & .030 & - & - \\
\hline
\end{tabular}

Appendix D. Table 2: The effects of ruling/opposition status on elite negative partisanship (SVM).

Elite Negative Partisanship

\begin{tabular}{lcc}
\hline & Binary Logistic Regression & OLS \\
\hline Intercept & $-.34(.05)^{* * *}$ & $.03(.04)$ \\
Status (Opposition) & $.36(.01)^{* * *}$ & $.07(.01)^{* * *}$ \\
Num. of Followers & $.04(.00)^{* * *}$ & $.02(.00)^{* * *}$ \\
Num. of Friends & $.04(.00)^{* * *}$ & $.02(.00)^{* * *}$ \\
Time (04:00 - 07:59) & $-.45(.06)^{* * *}$ & - \\
Time (08:00 - 11:59) & $-1.09(.07)^{* * *}$ & - \\
Time (12:00 - 15:59) & $-.13(.02)^{* * *}$ & - \\
Time (16:00 - 19:59) & $-.06(.02)^{* * *}$ & - \\
Time (20:00 - 23:59) & $-.16(.02)^{* * *}$ & - \\
\hline$N$ & 112491 & .003 \\
$R^{2}$ & - & .085 \\
$R^{2}$ (Nagelkerke) & .018 & - \\
\hline
\end{tabular}

Note: Cell entries are regression coefficients with associated standard errors in parentheses. ${ }^{*} p<.05,{ }^{* *} p<.01$, $* * * p<.001$. 
Appendix D. Table 3: The effects of positive/negative partisanship on the number of likes and retweets (SVM).

\begin{tabular}{lcc} 
& Likes & Retweets \\
\hline Intercept & $-6.02(.05)^{* * *}$ & $-6.21(.04)^{* * *}$ \\
Type (Negative Out-party) & $.45(.01)^{* * *}$ & $.64(.01)^{* * *}$ \\
Partisanship (Rep.) & $.30(.01)^{* * *}$ & $.33(.01)^{* * *}$ \\
Num. of Followers & $.93(.00)^{* * *}$ & $.84(.00)^{* * *}$ \\
Num. of Friends & $-.07(.00)^{* * *}$ & $-.06(.00)^{* * *}$ \\
Controlling for topic & Yes & Yes \\
Controlling for time & Yes & Yes \\
\hline$N$ & 170424 & 170424 \\
$R^{2}$ & .571 & .546 \\
\hline
\end{tabular}

Note: Cell entries are regression coefficients with associated standard errors in parentheses. 155 tweets were excluded because they had no predicted topics. ${ }^{*} p<.05,{ }^{* *} p<.01,{ }^{* * *} p<.001$. 